\title{
CRÓNICA DE UN ENTERRATORIO DEL HOLOCENO MEDIO EN LA LOCALIDAD CERRO DE LOS VIEJOS (PROVINCIA DE LA PAMPA, ARGENTINA). IMPLICANCIAS PARA LA REGIÓN PAMPEANA Y EL SECTOR CENTRO-MERIDIONAL DE LA DIAGONAL ÁRIDA SUDAMERICANA
}

\author{
CHRONICLE OF A MIDDLE HOLOCENE BURIAL IN THE CERRO DE LOS \\ VIEJOS LOCALITY (LA PAMPA PROVINCE, ARGENTINA). IMPLICATIONS FOR \\ THE PAMPEAN REGION AND CENTRAL-SOUTHERN SECTOR OF THE SOUTH \\ AMERICAN ARID DIAGONAL
}

\author{
Mónica A. Berón ${ }^{1,2}$, Florencia N. Paez ${ }^{1}$, Manuel P. Carrera Aizpitarte ${ }^{1,2}$ y Eliana N. Lucero ${ }^{1,3}$
}

\begin{abstract}
En este trabajo se informa sobre el hallazgo de un enterratorio de singulares características, correspondiente al Holoceno Medio, en la región central de Argentina (subregión Pampa Occidental). Su cronología aporta valiosa información para el conocimiento del proceso de poblamiento de una región semiárida, con escasez de datos disponibles para este periodo. Además, el entierro presenta un abundante y variado ajuar mortuorio, que se compara con otro caso similar de la subregión. A partir de ello se sintetiza información arqueológica de la macro región de estudio ( 32 a $39^{\circ} \mathrm{LS}$ ), se analizan modelos sobre patrones de movilidad y ocupación inicial de espacios, se describen sesgos y tendencias generales en los procesos de poblamiento y se delinean regularidades en las modalidades de entierro del Holoceno Medio de Pampa Occidental.
\end{abstract}

Palabras claves: Holoceno Medio, Diagonal Árida, ecorrefugios, ambientes acuáticos, exploración inicial, Pampa Occidental.

The aim of this paper is to report on the characteristics of a singular burial corresponding to the Middle Holocene, in the central region of Argentina (Western Pampa subregion). Its chronology provides valuable information for the knowledge of settlement processes in this semi-arid region, where there is currently scarce data available for this period. The burial possesses abundant and varied grave goods, comparable with those in another similar burial in the subregion. Archaeological information from the macro region under study ( 32 to $\left.39^{\circ} \mathrm{LS}\right)$ is summarized, and models of mobility patterns and initial occupation of spaces are analyzed, including biases and general trends in the population processes. Finally, regularities in the modalities of Middle Holocene burials from the Western Pampa are outlined.

Key words: Middle Holocene, Arid Diagonal, eco-refuges, aquatic environments, initial exploration, Western Pampas.

Un amplio territorio de la República Argentina se inscribe en la llamada Diagonal Árida Sudamericana (en adelante DAS). A lo largo de la misma y con algunas diferencias se suceden ambientes desérticos y semidesérticos desde la Puna hasta la Patagonia. La constante que los identifica son las bajas precipitaciones, grandes amplitudes térmicas y la escasez de agua potable en superficie. Una extensa porción del centro- sur de la DAS atraviesa al territorio pampeano, desde el paralelo $36^{\circ} \mathrm{LS}$ hasta su límite sur en el Río Colorado, abarcando la transición entre las llanuras sedimentarias y las mesetas patagónicas. Como límite oriental se establece el desarrollo de los bosques de caldén, mientras que al oeste, el semidesierto pampeano constituye una prolongación de las áreas desérticas de Mendoza, particularmente de la Payunia (Medus y Aráoz 1982).

\footnotetext{
${ }^{1}$ IDECU (CONICET - Universidad de Buenos Aires); Museo Etnográfico Juan B. Ambrosetti, Facultad de Filosofía y Letras, Universidad de Buenos Aires, Ciudad Autónoma de Buenos Aires, Argentina. monberon@ retina.ar; fnatapaez@gmail.com; mcarreraaizpitarte@gmail.com; eli.lucero2008@gmail.com

${ }^{2}$ Facultad de Ciencias Sociales, Universidad Nacional del Centro de la Provincia de Buenos Aires, Olavarría, Argentina. ${ }^{3}$ Agencia Nacional de Promoción Científica y Tecnológica, Ciudad Autónoma de Buenos Aires. Buenos Aires, Argentina.
} 
Las características áridas y semiáridas de la provincia de La Pampa no ofrecen condiciones para que se desarrolle una red hidrográfica local de carácter permanente. El único río de régimen anual es el Colorado (Figura 1). Sin embargo, esto no impidió la colonización humana de este espacio. Los grupos cazadores-recolectores que habitaron la subregión de Pampa Occidental implementaron diferentes estrategias para hacer frente a estas limitaciones ambientales, y desarrollaron sus actividades en torno a recursos hídricos sustitutos, como campos de dunas, lagunas temporales, estanques y manantiales, lo que dio lugar a la ocupación recurrente de los lugares más favorecidos para el asentamiento (Berón 2016; Garvey 2008; Schlanger 1992; Veth 2005). Dichas estrategias resultaron vitales en los momentos de exploración inicial de un paisaje. Durante esta primera etapa, que Miotti et al. (2015) denominan "aprendizaje locacional", se realiza, a escala local del poblamiento regional, el reconocimiento y ubicación de los recursos y se seleccionan hitos geográficos y rasgos topográficos reconocibles para establecer rutas desde lugares ya conocidos.
A escala espacial más amplia, los modelos de colonización humana en torno a ambientes acuáticos propuesto por Erlandson (2001) y desarrollado por Miotti (2006) para Sudamérica son acordes con el planteo de este trabajo. La autora propone como opciones de colonización inicial este tipo de ambientes continentales, a partir de un modelo de poblamiento centrípeto ramificado que considera diversos puntos de ingreso desde la costa marítima y las desembocaduras de las grandes cuencas fluviales hacia el interior del continente. Postula que se trata de un proceso lento, con avances, retrocesos y recolonización de algunas áreas, con territorialidades definidas culturalmente (Miotti 2006).

Los primeros asentamientos en la subregión ofrecen registros efímeros para el Holoceno Temprano (11700-8200 cal AP sensu Walker et al. 2012) y Medio (8200-4200 cal AP sensu Walker et al. 2012), en cuatro loci principales: Casa de Piedra 1, Tapera Moreira 1, El Carmel y Cerro de los Viejos (Berón 2004; Berón et al. 2015; Gradin et al. 1984; Paez et al. 2020). Los grupos se asentaron en espacios donde los recursos estaban concentrados, pero circularon en

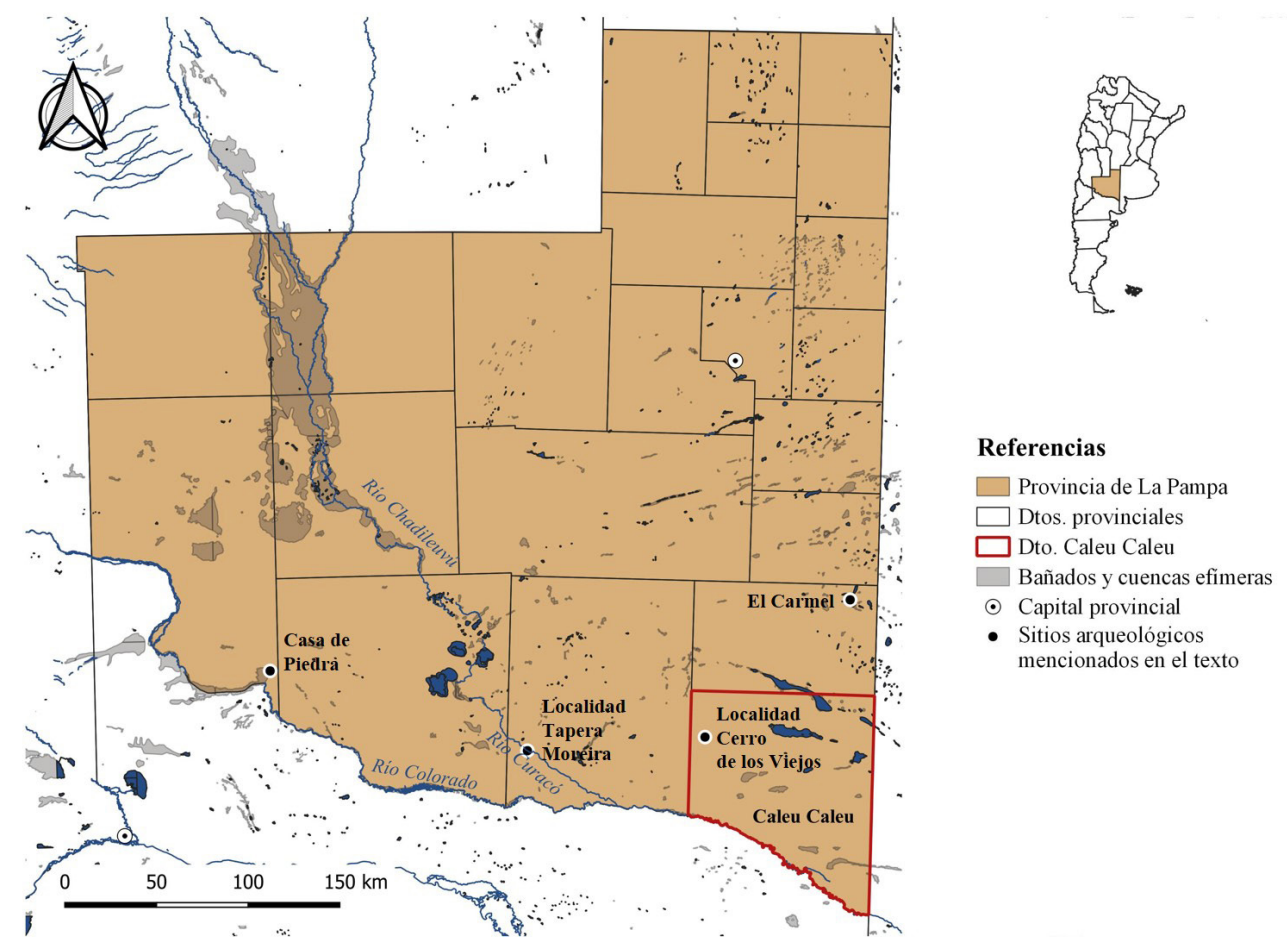

Figura 1. Ubicación del área de estudio y de los sitios de Pampa Occidental mencionados en el texto.

Location of the research area and the Western Pampa archaeological sites mentioned in the paper. 
paisajes con fisiografías variadas. Ambos periodos se caracterizan por baja densidad demográfica y artefactual, escasa variabilidad de grupos tipológicos y de recursos líticos, cierta selectividad de materias primas de excelente calidad para la confección de armas, indicios de asentamientos semi-permanentes y explotación de recursos faunísticos de alto retorno (Gradin et al. 1984; Salemme y Berón 2003). A inicios del Holoceno Tardío (desde 4200 cal AP sensu Walker et al. 2012) se estabilizaron las condiciones climáticas actuales, se registró un crecimiento demográfico y se intensificó la explotación de los recursos locales. Aparecieron estructuras formales de entierro y se incrementó la presencia de elementos extra-regionales como signo de interacciones a gran escala. En este contexto, progresivamente se incorporaron nuevas tecnologías, como alfarería, artefactos de molienda, manufactura de adornos malacológicos, metálicos, entre otras. Además se diversificó la dieta de las poblaciones con la ampliación de recursos locales y la incorporación de otros obtenidos por intercambio u otras estrategias (Berón et al. 2017). Como resultado del conjunto de dataciones y evidencia cultural, se ha establecido que la escala de tiempo en que sucedieron los eventos de exploración, colonización y uso del espacio en el centro-sur de La Pampa abarca desde fines del Holoceno Temprano, parte del Holoceno Medio, y todo el Holoceno Tardío (Berón et al. 2020; Borrero 1989-1990; Miotti 2006). Sin embargo, la información sobre el Holoceno Temprano y Medio sigue siendo escasa en esta y otras regiones, particularmente aquellas comprendidas en la zona cordillerana de la DAS.

El Holoceno Medio, a nivel macrorregional, fue durante décadas un periodo caracterizado por un pronunciado silencio arqueológico. Ello dio lugar a un debate sobre las posibles causas de la escasez de información en varias regiones del centro de Argentina y el centro-sur de Chile (29 a $35^{\circ} \mathrm{LS}$, Barberena et al. 2017; Barrientos y Pérez 2002; Cortegoso
2005; Durán y Mikkan 2009; Favier Dubois 2006; Favier Dubois et al. 2017; García 2005; Martínez et al. 2015; Méndez et al. 2015, 2016; Messineo et al. 2019; Neme y Gil 2009). En los últimos años esta situación ha comenzado a revertirse con la identificación de sitios con cronologías acordes. En relación a ello, el objetivo de este trabajo es presentar un nuevo sitio de enterratorio, denominado CLV2, ubicado en la Localidad Arqueológica Cerro de los Viejos (CLV) en el área de Bajos sin Salida de la provincia de La Pampa. El mismo cuenta con una serie de características distintivas y una cronología que lo ubica en el Holoceno Medio (ca. 6000 años AP, Tabla 1). Se trata de una de las evidencias más tempranas de presencia humana en la subregión y la más antigua del área de Bajos sin Salida, que lo posicionan como un dato sustantivo para comprender el proceso de poblamiento humano de Pampa Occidental.

\section{Caracterización Geográfica del Área de Bajos Sin Salida}

Solo dos cuencas fluviales atraviesan la provincia de La Pampa. Una de ellas es el Río Colorado, de carácter permanente y origen alóctono, que se ubica en el límite sur. El otro es el sistema Atuel-SaladoChadileuvú-Curacó, de régimen irregular, ya que permanece seco la mayor parte del año. Su origen es alóctono y desagua en el Río Colorado por medio del Curacó. Importantes procesos morfogenéticos y antrópicos provocaron la degradación de esta red fluvial (Giraut et al. 2006; INTA 1980).

La Localidad Arqueológica Cerro de Los Viejos $\left(38^{\circ} 28^{\prime} \mathrm{LS} ; 4^{\circ} 26^{\prime} \mathrm{LO}\right)$ se ubica en el departamento de Caleu Caleu, a ca. $25 \mathrm{~km}$ de la localidad de Cuchillo-Có, en el área de Bajos sin Salida, sudeste de la provincia de La Pampa (Figura 1). El área forma parte de la Cuenca del Colorado, que constituye un ámbito de transición Pampeano-Patagónico donde predominan condiciones climáticas áridas-

Tabla 1. Cronología y datos isotópicos de CLV2.

CLV2 chronology and isotopic data.

\begin{tabular}{|c|c|c|c|c|c|c|c|c|c|c|}
\hline $\begin{array}{c}\text { UGAMS } \\
\#\end{array}$ & Material & $\delta^{13} \mathrm{C}_{\mathrm{a}} \%$ & $\delta^{18} \mathrm{O}_{\mathrm{a}} \%$ & $\delta^{13} \mathrm{C}_{\mathrm{c}} \%$ & $\begin{array}{c}\delta^{15} \mathrm{~N}_{c} \\
\% 0\end{array}$ & $\mathrm{C} / \mathrm{N}$ & $\begin{array}{l}{ }^{14} \mathrm{C} \text { age, } \\
\text { years BP }\end{array}$ & \pm & Cal $1 \Sigma \mathrm{BP}$ & $\mathrm{Cal} 2 \Sigma \mathrm{BP}$ \\
\hline 38074 & $\begin{array}{l}\text { 3er. molar inferior } \\
\text { izquierdo }\end{array}$ & $-9,75$ & 1,32 & $-16,27$ & 12,35 & 3,16 & 5160 & 20 & 5909- 5928 & $\begin{array}{l}5899-5943 \\
5971-5984\end{array}$ \\
\hline
\end{tabular}


semiáridas, con una precipitación de 400 mm/año y presencia de suelos arenosos y pedregosos (Cioccale 1999; Daus 1959; Difrieri 1958; INTA 1980). Desde el punto de vista fitogeográfico, están presentes las provincias del Espinal y del Monte (Cabrera 1960). La fauna está enmarcada dentro del Distrito Pampásico, subdistrito puntano-pampeano (Medus et al. 1982) y ofrece variedad de especies de carnívoros, herbívoros, roedores, edentados, reptiles, aves y batracios. De acuerdo al registro arqueológico, también formaban parte de la fauna local el guanaco (Lama guanicoe) y el venado de las pampas (Ozotoceros bezoarticus), el primero con poblaciones actualmente muy reducidas y el segundo completamente ausentes (Bastourre y Salazar Siciliano 2012; Salemme y Berón 2003).

Geomorfológicamente, el área corresponde a una llanura con sucesión de niveles escalonados en sentido oeste-este. El relieve se diferencia al de áreas aledañas, dado que su disección es más marcada y los bajos sin salida son abundantes. La característica genética de esta unidad está dada por la acción de los procesos vinculados a los paleocauces del Río Colorado, cuyos escurrimientos hídricos concentrados dieron lugar a un relieve posteriormente sometido al modelado eólico (Folguera et al. 2015; Martínez et al. 2012; Melo et al. 2003). Este tipo de morfogénesis ha sido responsable de los rasgos fundamentales que son distintivos de la entidad y que están representados por las depresiones y Bajos sin Salida. Algunos de estos bajos o lagunas proporcionan importantes volúmenes de cloruro de sodio. El mayor interés de estos ambientes es que son muy dinámicos y contienen cuerpos de agua, cuyo régimen puede ser transitorio o permanente. Esto último genera ecosistemas concentradores de recursos (vegetación y fauna diferentes del entorno), que fueron caracterizados como ecorrefugios (sensu Núñez et al. 1999) y aplicados al contexto pampeano en Berón et al. (2020).

La mayor parte del área de investigación está incluida en el Mar de Arena Pampeano o Campo de Dunas Pampeanas definido por Iriondo y Kröling (1995). Este amplio espacio es un entorno geomorfológico heterogéneo que, posteriormente, fue dividido por Zárate y Tripaldi (2012) en diferentes unidades eólicas, según la naturaleza de los depósitos. De acuerdo a esta propuesta el área de estudio está comprendida en dos unidades: Mantos de Arena y Campos de Dunas de la Pampa Occidental y la fracción septentrional de los Mantos de Arena y Campos de
Dunas de la Patagonia Norte y Pampeana Sur. Gran parte de estas unidades se ubican dentro del sector centro meridional de la DAS (Bruniard 1982; Villagrán e Hinojosa 1997).

\section{Reconstrucción Paleoclimática}

En la macro área, ubicada entre los paralelos 32 y $39^{\circ} \mathrm{LS}$ y desde la zona cordillerana hasta la costa atlántica, se observan diferencias en las reconstrucciones paleoclimáticas realizadas para el periodo comprendido entre finales del Pleistoceno y el Holoceno Medio. Estas diferencias responden a las variaciones regionales existentes y a los proxies considerados (Zárate 2010).

\section{Pleistoceno Final y transición hacia el Holoceno}

Diferentes proxies indican que durante la transición Pleistoceno Final-Holoceno prevalecieron condiciones semiáridas en el sector medio y oeste de Norpatagonia (Schäbitz 2003) y áridas en el sudeste de Mendoza (Krömer 1996), al igual que en el sector oriental de Norpatagonia en el cual está comprendida el área de Bajos sin Salida (Schäbitz 2003). En la región pampeana, se registran condiciones semiáridas-áridas, frías y secas que muestran progresivamente un aumento en la temperatura y humedad durante el Holoceno Temprano (Aguirre y Whatley 1995; Martínez et al. 2013; Quattrocchio et al. 2008; Tonello y Prieto 2010; Tonni et al. 2003; Zárate 1997; entre otros). Durante este periodo, en gran parte de la región pampeana, se produce la removilización de sedimentos procedentes del Mar de Arenas (Iriondo y Kröhling 1995). Por su parte, la presencia de climas fríos y secos produjo un descenso del nivel del océano Atlántico hasta la cota de $-125 \mathrm{~m}$, retrayendo la paleocosta unos $170 \mathrm{~km}$ hacia el este (Melo et al. 2003 y las citas mencionadas allí). En el sector occidental de las sierras de Lihué Calel y del área de confluencia de los actuales ríos Chadileuvú y Colorado se inició un incremento en la capacidad hídrica y de transporte de los ríos (Melo et al. 2003), lo cual da cuenta de la interconectividad de las cuencas durante este periodo.

\section{Holoceno Temprano}

En la precordillera mendocina y el Valle del Atuel se describen condiciones áridas y bajas temperaturas para este periodo (García et al. 1999; Zárate y Paez 
2002). Estas evidencias son concordantes con el esquema original propuesto por Markgraf (1983), a partir de los estudios realizados en Gruta del Indio, La Guevarina y Puesto Vicencio.

Para el sudoeste de la provincia de Buenos Aires, la información paleoclimática indica un periodo caracterizado por una significativa diversidad de ambientes, con recursos distribuidos heterogéneamente tanto espacial como temporalmente. A partir de ca. 10000 años AP el clima habría comenzado a mejorar (Aramayo et al. 2005; Grill et al. 2007; Quattrocchio et al. 2008; Zárate et al. 1998). Este pulso de óptimas condiciones puede ser identificado en la estratigrafía de este sector de la provincia de Buenos Aires mediante la presencia de superficies de estabilización del paisaje, formación de suelos y de estanques temporarios (Borel et al. 2001; Holliday et al. 2003; Johnson et al. 1998). Consecuentemente, con respecto a los cambios del nivel del mar, Aliotta y Perillo (1990, en Melo et al. 2003) señalan que entre ca. 9500 y 7500 años AP, se inició un ascenso que llegó aproximadamente a la cota de entre -12 y $-18 \mathrm{~m}$. Por otra parte, para el sudeste de La Pampa y noreste de Patagonia, Schäbitz (2003) propone que las condiciones habrían sido cálidas y semiáridas, mientras que en el centro y el oeste, se caracterizaron por ser cálidas y áridas.

\section{Holoceno Medio y Tardío}

Los registros multiproxies indican fluctuaciones significativas en el nivel de los lagos en los Andes centrales, actividad eólica en las Pampas, intervalos de erosión de suelos o inestabilidad del paisaje y cambios en la cobertura vegetal que indican condiciones secas entre ca. 8000 y 3000 años AP. Esto fue registrado en numerosas áreas desérticas, semidesérticas y semiáridas/subhúmedas del sur de Sudamérica (Gil et al. 2005; Grimm et al. 2001; Mancini et al. 2005; Zárate 2002; Zárate et al. 2005). A su vez, ocurre un fenómeno climático a nivel mundial, conocido como Óptimo Climático o Hypsitermal (González y Weiler 1983). Si bien dicho evento no fue totalmente sincrónico ni tuvo las mismas características en ambas latitudes (Mann 2002), su rasgo principal fue la presencia de condiciones más cálidas y secas que las actuales. En el sur de Mendoza (Gruta del Indio), los datos polínicos indican que entre ca. 9000 y 5000 años
AP habría habido un significativo descenso en las precipitaciones, junto a un aumento en la temperatura, lo que produjo un marcado periodo de extrema aridez (Markgraf 1989, 1993). Pascual y Bondesio (1981) indican un periodo de óptima humedad y temperatura entre ca. 7000 y 5000 años AP para latitudes que van desde el sur de Patagonia hasta los andes cuyanos, a lo que le sigue una fase muy árida entre ca. 5000 y 4000 años AP, coincidente con el desarrollo de extensos mantos de sedimentos eólicos (Aguirre y Whatley 1995; Muhs y Zárate 2001; Zárate y Flegenheimer 1991). Estos datos concuerdan con los generados por Bonadonna et al. (1995) y Prieto (1996) en provincia de Buenos Aires, y lo señalado por Martínez (2017).

El Óptimo Climático coincide con la máxima transgresión marina postglacial ocurrida entre ca. 8000 y 6000 años AP (Clark y Bloom 1978; Codignotto et al. 1992; Gómez y Perillo 1995; González 1984). En La Pampa, evidencias de la transgresión marina fueron registradas en Laguna La Amarga (Dpto. Curacó; Cordini 1967), donde se recuperaron foraminíferos y en Laguna La Colorada Grande (Dpto. Caleu Caleu), apartir de la presencia de sedimentos marinos cuaternarios (Cordini 1967).

En el sudeste bonaerense, la transgresión marina se verificó en la desembocadura de distintos cursos fluviales (González et al. 1983; Isla et al. 1986; Quattrocchio et al. 2008). Hacia los ca. 7000 años AP el mar ascendió paulatinamente a valores altimétricos semejantes a los actuales, y para ca. 6000 y 5500 años AP la transgresión alcanzó cotas entre 5 y 12 m sobre el nivel actual (Melo et al. 2003). De acuerdo con Melo et al. (2003), durante este periodo, el territorio comprendido entre el sudeste de la provincia de $\mathrm{La}$ Pampa y el estuario de Bahía Blanca, se caracterizó por una intensa actividad de la paleored de drenaje del curso inferior del Río Colorado. El aporte hídrico de estos cursos habría comenzado a disminuir paulatinamente a partir de ca. 5000 años AP, hasta casi desaparecer en ca. 3000 años AP (Melo et al. 2003).

Durante el Hyspitermal (ca. 7000 y 5000 años AP), en el sector oriental de Norpatagonia se registran bajas precipitaciones anuales (Schäbitz 2003), mientras que para la subregión Pampa Oriental se han propuesto condiciones húmedas que alternan con secas (Tonni et al. 1999). Entre ca. 5000 y 3000 años AP tuvo lugar un incremento de las precipitaciones, que generó en el área una fase transicional desde condiciones áridas a semiáridas, así como el desarrollo de salinas en los 
bajos (Schäbitz 2003). Alrededor de ca. 4000 y 3000 años AP, se estabilizaron las condiciones climáticas actuales, el mar descendió hasta alcanzar valores estables entre las cotas de 2 a $3 \mathrm{~m}$ (González y Weiler 1983; Markgraf 1989, 1993; Schäbitz 2003) y se inició el proceso de desaparición de los antiguos cauces del Río Colorado (Melo et al. 2003). Además, la formación de dunas jóvenes y la removilización de arena indican que durante este lapso ocurrió un incremento de las condiciones de aridez (Schäbitz 2003). Entre ca. 3500 y 1000 años AP en la llanura chaco-pampeana se estableció un clima seco, semiárido y se produjo una deflación generalizada de los sedimentos superficiales y su redepositación en forma de manto de limo y arena, con campos de dunas asociados (Iriondo 1990; Iriondo y García 1993).

El sudeste de la provincia de La Pampa ha sido una de las áreas más afectadas por la deflación, y se caracteriza por el pequeño espesor de suelo y arena que queda en la superficie; el viento erosionó y transportó los sedimentos, revelando material subyacente consolidado (costras calcáreas, rocas volcánicas). Es la intensa acción del viento la que afecta principalmente el estado de la evidencia arqueológica en el área, que en su mayoría aparece en la superficie del suelo, o bien porque quedaron expuestos o porque nunca se sometieron a procesos de enterramiento. Hay pocos sitios estratificados, con extensas secuencias cronológicas culturales. En consecuencia, en estos entornos semiáridos, las dinámicas ambientales significativas han producido un registro arqueológico fragmentario (Berón 2016; Martínez y Martínez 2011).

\section{Caracterización Geomorfológica de la Localidad Cerro de los Viejos}

La geoforma dominante es un cerro de forma elíptica, con eje en rumbo NO-SE, aproximadamente de $1,5 \mathrm{~km}$ por $1 \mathrm{~km}$, que está en contacto con depósitos sedimentarios recientes e integra el basamento ígneo-metamórfico de la provincia de La Pampa. Se trata de un afloramiento granitoide que alcanza los $216 \mathrm{msm}$, siendo la elevación de mayor altura en la zona (Figura 2 A). Su topografía se destaca en el paisaje y le confiere características particulares al ambiente del área (Folguera et al. 2015; Sato et al. 1996; Tickyj y Llambías 1994; Tickyj et al. 1997).

Presenta un microclima que favorece la permanencia de condiciones más húmedas que su entorno durante largos periodos, ya que las aguas de lluvia se concentran en cañadones y hoyadas rocosas, al punto de favorecer el desarrollo de vegetación que requiere estas condiciones, como algunas especies de Pteridophyta, comúnmente denominadas helechos. Entre ellas se ha detectado Adiantum thalictroides, Blechnum australe (de la Sota 1985). Interesa destacar que este tipo de plantas se han encontrado en pocas zonas serranas húmedas, siendo las Sierras de Lihué Calel y el Cerro de los Viejos los únicos lugares de La Pampa donde están presentes. También se encuentran diversas especies de hongos. Además hay manantiales permanentes y surgentes estacionales que en condiciones favorables conforman un sistema hídrico considerable. Todas estas condiciones permiten el desarrollo de bosques de chañares, molles y en ciertos periodos se conforma un profuso sotobosque.

\section{Antecedentes e Historia de las Investigaciones Arqueológicas}

Las primeras investigaciones en Cerro de los Viejos fueron desarrolladas por Ernesto Piana y colaboradores en la década de 1970 (Piana 1981). Se detectaron indicios de ocupaciones humanas sobre la base de materiales arqueológicos superficiales tales como artefactos líticos, fragmentos cerámicos, restos óseos quemados, artefactos de molienda y un mortero múltiple. Pero el interés de estas investigaciones se centró en el relevamiento y análisis de un conjunto de seis construcciones arquitectónicas de piedra y tierra que fueron interpretadas como represas, para abrevar animales en la época en que los aborígenes se integraron en una red de amplia escala, para el traslado y la comercialización de ganado entre las llanuras bonaerenses y la Araucanía chilena, durante el periodo denominado "ciclo del ganado", es decir entre los siglos XVII y XIX aproximadamente (Piana 1981). Esta idea está apoyada por abundantes datos etnohistóricos (de Jong y Cordero 2016; Mandrini 1984; Pinto Rodriguez 1996) y arqueológicos (Goñi 1986-87; Madrid 1991; Pedrotta 2016), sumado al hecho que Cerro de los Viejos se ubica en una de las principales rastrilladas o caminos indígenas.

En 1996la Dra. Alicia Tapia, el Dr. Rafael Curtoni y el Arq. Miguel García fueron comisionados por la entonces Subsecretaría de Cultura de la provincia de La Pampa para realizar un relevamiento del estado de preservación de las represas. Entre los años 1998 


y 2009 dos de los autores (MB y MCA) realizaron incursiones esporádicas a CLV, con un grupo de colaboradores. La prospección realizada en 1998 estuvo motivada por una denuncia de acciones depredatorias por parte de cazadores furtivos. Como resultado de ello se registró un enterratorio denominado CLV1 (38 $28^{\circ}$ ' 42, 1' LS; 642' $19,8^{\prime \prime}$ LO), cuyo esqueleto postcreaneano fue localizado en el perfil de un cañadón, pero el cráneo se hallaba ausente, ya que había sido retirado por un huaquero. El enterratorio fue dejado in situ para su futura investigación, pero se registró fotográficamente y se constató la presencia de una piedra laja por encima del cráneo ausente. Dicho cráneo fue posteriormente recuperado de manos del huaquero. Durante la prospección realizada en 2009, se intentó recuperar CLV1, pero los restos óseos habían sido arrastrados por la acción hídrica intensa que afecta a los cañadones en épocas de lluvia. Desde 2017 hasta el presente se intensificaron los trabajos de campo en CLV. Como resultado de ello se han identificado dos nuevos enterratorios (CLV2 y 3, Lucero et al. 2020 y este trabajo), un contexto doméstico (CLV5, en proceso de análisis) y se realizó un estudio detallado del mortero múltiple, considerado de uso transgeneracional (CLV4, Paez et al. 2020) y de las seis construcciones arquitectónicas, interpretándolas actualmente como un sistema de manejo del agua compuesto por represas y esclusas (Paez et al. 2019; Figura 2). La información generada indica que CLV constituye una Localidad Arqueológica que reúne, en un ambiente naturalmente circunscrito y culturalmente modelado, un conjunto diferenciado de manifestaciones culturales que reflejan las trayectorias de las poblaciones que lo habitaron a lo largo de los últimos 6000 años y hasta tiempos históricos.

\section{Descripción y Cronología del Entierro}

El entierro denominado CLV2 (38 $28^{\prime} 42,5^{\prime \prime}$ LS; 64⒉ $19,2^{\prime}$ " LO) fue hallado en el sector sureste del cerro, asomando sobre el perfil de un cañadón de erosión aluvional, como consecuencia de la acción hídrica. Se trata del mismo cañadón en el que se localizó el entierro CLV1, a unos 20 $m$ de distancia entre sí. Las piezas expuestas eran mandíbula, algunos huesos largos y vértebras. También asomaban del perfil dos grandes lajas que formaban parte del recubrimiento del enterratorio, repitiendo el patrón de CLV1. Se decidió extraerlo ante la posibilidad de pérdida de piezas por el arrastre de las aguas de lluvia que escurren por dicho cañadón, sobre la base de la experiencia previa.

Para la extracción de CLV2 se planteó una cuadrícula de $2 \mathrm{~m}$ de lado en la superficie del suelo actual, por encima del cañadón. La excavación se realizó por niveles artificiales de 0,10 m hasta alcanzar la inhumación. No se registraron hallazgos en los sedimentos precedentes, que fueron tamizados con malla fina, en seco. En cambio se registró presencia de carbonatos y acción de raíces.

A $1,80 \mathrm{~m}$ de profundidad del suelo actual se detectaron algunas de las lajas que cubrían y rodeaban el enterratorio. El entierro es primario simple y se hallaba a una profundidad de $1,94 \mathrm{~m}$ del suelo actual, en posición decúbito lateral derecho, con orientación noroeste, cubierto y rodeado por siete lajas. Se pudo observar que los elementos óseos presentes se encontraban en su mayoría articulados $\mathrm{y}$ sin desplazamiento de las piezas esqueletales preservadas. El mismo apoyaba a 2,16 $\mathrm{m}$ de profundidad. Si bien el cráneo se hallaba ausente al momento del hallazgo, fue recuperado posteriormente debido a que un poblador de la zona lo reenterró en las proximidades del sitio al notar que la erosión hídrica lo estaba exponiendo. El individuo inhumado portaba un importante y complejo ajuar mortuorio a la altura del pecho. Se considera ajuar mortuorio a aquellos elementos preparados, acomodados o agrupados especialmente para ser depositados con el individuo en el momento de la inhumación (Berón 2018).

El entierro fue fechado a partir de un tercer molar inferior izquierdo, siguiendo el protocolo desarrollado por el equipo de trabajo ${ }^{1}$ (Berón et al. 2009, 2013). El resultado del fechado es $5160 \pm 20$ años AP, UGAMS 38074 (diente). La calibración promediada por el laboratorio es de 5920 años antes del presente, lo que ubica este enterratorio en el Holoceno Medio (Walker et al. 2012). Además se obtuvieron valores isotópicos de $\delta^{13} \mathrm{Cap}, \delta^{13} \mathrm{C}_{\mathrm{col}}$, $\delta^{15} \mathrm{~N}_{\text {col }}$ y $\delta^{18} \mathrm{O}_{\text {ap }}$ en el Center for Applied Isotopes Studies, University of Georgia ${ }^{2}$ (Tabla 1).

De acuerdo al análisis osteobiográfico y la metodología publicada por Lucero et al. (2020), el entierro corresponde a un individuo masculino, de 157-163 cm de estatura, cuya muerte acaeció a una edad madura (40 a 49 años). La presencia de hipoplasias del esmalte dental sugiere que durante su infancia (entre los tres y cuatro años de edad) 
habría padecido episodios de estrés metabólico (Goodman y Rose 1991; Hillson 1996; Lucero et al. 2020).

En cuanto a la dieta, los valores isotópicos de carbono y nitrógeno de CLV2 (Tabla 1) y su comparación con los datos de ecología isotópica conocidos para el área de Pampa Occidental, indican que durante su juventud (15 a 20 años) habría consumido recursos terrestres (Barberena et al. 2018). Esta dieta incluiría especialmente herbívoros consumidores de plantas C3 y/o CAM, como guanaco, venado, ñandú, representados en el registro faunístico local (Lucero et al. 2020). Los análisis de salud bucal y uso funcional del aparato masticatorio indican una dieta compuesta por alimentos duros y fibrosos, con partículas abrasivas y/o con bajo contenido de carbohidratos. La combinación de estos factores habría posibilitado que el estado de salud de la cavidad oral se mantuviera relativamente bueno hasta su avanzada edad (Lucero et al. 2020).

Por otra parte, el valor de $\delta^{18} \mathrm{O}$ (Tabla 1) muestra un enriquecimiento respecto al rango local de valores de agua generado para el área de Pampa Occidental (entre -4,2\% y -1,7\%o; sensu Barberena et al. 2018). Esto puede indicar que durante su juventud habría consumido aguas de precipitación local, aunque con valores de $\delta^{18} \mathrm{O}$ enriquecidos debido posiblemente a condiciones de mayor aridez que tuvieron lugar durante el Holoceno Medio. Finalmente, los datos relativos al estrés ocupacional permiten interpretar que el estilo de vida del individuo no habría requerido de usos intensivos ni reiterativos del cuerpo en tareas que implicaran un esfuerzo mecánico elevado y demandante (Lucero et al. 2020).

\section{Composición del Ajuar Mortuorio}

CLV2 presenta un abundante y variado ajuar mortuorio constituido por un total de 14 artefactos que representan una diversidad de materialidades (Tabla 2). El conjunto de elementos se halló ubicado a la altura del pecho, entre los miembros superiores (Figura 3). Los mismos se hallaban agrupados y superpuestos, seguramente a causa de haber sido depositados en algún contenedor de material orgánico, no conservado. Incluso algunos ítems presentaban inclinaciones de $45^{\circ}$, debido al fuerte agrupamiento (Figura 4). Si bien algunos de los elementos pudieron formar parte de la vida cotidiana del individuo inhumado, se considera que conforma un ajuar dada la intencionalidad de agruparlos en un contenedor y colocarlos sobre su pecho.

Entre ellos hay nueve artefactos líticos de diferente tipo. Tres son puntas de proyectil triangulares apedunculadas (Figura 5 A, B y C), dos de las cuales están en avanzado proceso de confección (Figura 5 A y B). Además hay una lasca angular, un cuchillo de filo doble y un canto rodado (Figura 5 G, H y I). En todos los casos la materia prima es sílice de similar coloración, pero con características macroscópicas diferentes. La sílice de las puntas de proyectil parece proceder de la misma fuente y en los tres casos se observan impurezas blanquecinas en el centro de la pieza. También hay tres núcleos de pequeñas dimensiones, similar coloración, uno bipolar agotado y dos con lascados aislados (Figura 5 D, E y F). La mayoría de los artefactos presenta reserva de corteza, lo que daría cuenta de una escasa disponibilidad de materia prima de calidad.

Otro importante componente del ajuar es un crayón de pigmento rojo oscuro, triangular poliédrico con tres caras planas, todas con estrías de uso (Figura 6 A). Se analizó su composición inorgánica mediante $\mathrm{XRD}^{3}$. El análisis revela un mineral a base de hierro, probablemente hematita ( $\mathrm{Fe} 2 \mathrm{O} 3$ ), ya que es el elemento mayoritario mientras que otros elementos como aluminio (Al), silicio ( $\mathrm{Si})$, azufre $(\mathrm{S})$, potasio $(\mathrm{K})$, calcio $(\mathrm{Ca})$, titanio $(\mathrm{Ti})$, vanadio $(\mathrm{V})$, cromo $(\mathrm{Cr})$, manganeso (Mn), cobalto (Co), galio (Ga), estroncio $(\mathrm{Sr})$, arsénico $(\mathrm{As})$, rubidio $(\mathrm{Rb})$, itrio $(\mathrm{Y})$, zirconio $(\mathrm{Zr})$ y cerio $(\mathrm{Ce})$, se encuentran en proporciones mucho menores que el hierro (Maier y Tomasini 2018).

Forma parte del ajuar un colgante conformado por una valva completa de un organismo de agua dulce, levemente modificada, con un orificio de suspensión en un extremo (Figura 6 B). Ha sido asignada al género Diplodon sp. y es posible que corresponda a alguna de las dos especies más comunes en la región, $D$. delodontus o $D$. chilensis, cuyo registro alcanza el sur de la provincia de Buenos Aires y norte de Patagonia. No pudo ser determinada con mayor precisión pues está fragmentada a la altura de la charnela (Torres et al. 2012; 2018).

Resulta singular la presencia de tres artefactos óseos confeccionados sobre primeras falanges de guanaco adulto (Lama guanicoe) (Tabla 2, Figura 7). Las mismas están modificadas antrópicamente en su extremo distal asemejando la forma de una 
Tabla 2. Descripción general de cada pieza del ajuar mortuorio de CLV2. Referencias: m: mapeo.

General description of each grave good from CLV2 . Reference: m: mapping.

\begin{tabular}{|c|c|c|c|c|c|c|c|}
\hline \multicolumn{4}{|c|}{ Descripción general } & \multicolumn{3}{|c|}{ Medidas (mm) } & \multirow{2}{*}{ Observaciones } \\
\hline$N^{o}$ Pieza & Grupo tipológico & Subgrupo/ tipo & Materia prima & Largo & Ancho & Espesor & \\
\hline $\mathrm{m} 56$ & Pta. Proyectil & Apedunculada & Sílice & 42,25 & 26,97 & 8,9 & $\begin{array}{l}\text { Triangular de base rectilínea, } \\
\text { adelgazada }\end{array}$ \\
\hline m64 & Pta. Proyectil & Apedunculada & Sílice & 37,17 & 20,91 & 7,95 & $\begin{array}{l}\text { Triangular de base rectilínea, } \\
\text { adelgazada }\end{array}$ \\
\hline m59 & Pta. Proyectil & Apedunculada & Sílice & 41,04 & 25,94 & 9,34 & $\begin{array}{l}\text { Triangular de base convexilínea } \\
\text { simple, adelgazada }\end{array}$ \\
\hline $\mathrm{m} 57$ & Cuchillo & Bilateral & Sílice & 41,78 & 20,05 & 4,39 & Doble alterno \\
\hline $\mathrm{m} 58$ & Núcleo & Bipolar & Sílice & 19,45 & 21,83 & 8,06 & $\begin{array}{l}\text { Bipolar agotado con reserva de } \\
\text { corteza }\end{array}$ \\
\hline m62 & Núcleo & $\begin{array}{l}\text { Con lascados } \\
\text { aislados }\end{array}$ & Sílice & 31,02 & 24,9 & 12,58 & Con reserva de corteza \\
\hline $\mathrm{m} 60$ & Núcleo & $\begin{array}{l}\text { Con lascados } \\
\text { aislados }\end{array}$ & Sílice & 30 & 26 & 11 & Muy rodado, con pátina \\
\hline $\mathrm{m} 43$ & Lasca & Angular & Sílice & 24 & 31 & 9 & - \\
\hline m63 & Canto rodado & & Sílice & 32 & 17 & 15 & - \\
\hline m65 & Pigmento & Crayón & Hematita & 26,2 & 9 & 9 & $\begin{array}{l}\text { Presenta estrías de uso en todas las } \\
\text { caras }\end{array}$ \\
\hline $\mathrm{m} 42$ & Adorno & Colgante & $\begin{array}{l}\text { Valva } \\
\text { Diplodon sp. }\end{array}$ & 70 & 45 & 13 & $\begin{array}{l}\text { Presenta un orificio circular } \\
\text { (fragmentado) en uno de los extremos }\end{array}$ \\
\hline m61 & Instrumento óseo & desconocido & $\begin{array}{l}\text { Falange Lama } \\
\text { guanicoe }\end{array}$ & 63,8 & 22 & - & Extremo plano convexo muy alisado \\
\hline $\mathrm{m} 41$ & Instrumento óseo & desconocido & $\begin{array}{l}\text { Falange Lama } \\
\text { guanicoe }\end{array}$ & 83 & 22 & - & Extremo plano convexo muy alisado \\
\hline $\mathrm{m} 40$ & Instrumento óseo & desconocido & $\begin{array}{l}\text { Falange Lama } \\
\text { guanicoe }\end{array}$ & 78,5 & 24 & - & Preforma \\
\hline
\end{tabular}

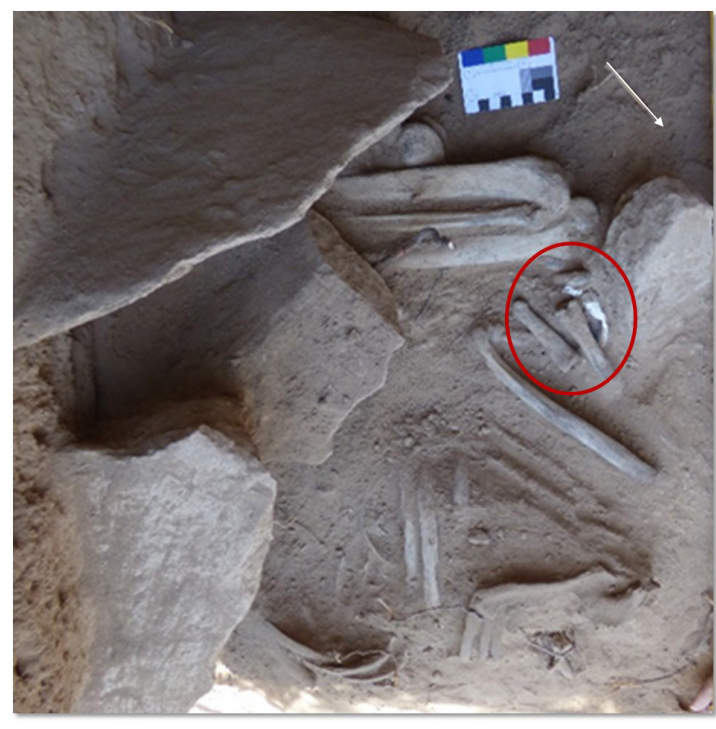

Figura 3. Imagen del enterratorio CLV2, con lajas asociadas. Circulado en rojo, posición in situ del ajuar mortuorio.

CLV2 burial image, with associated slabs. Circled in red is the in-situ position of the grave goods.

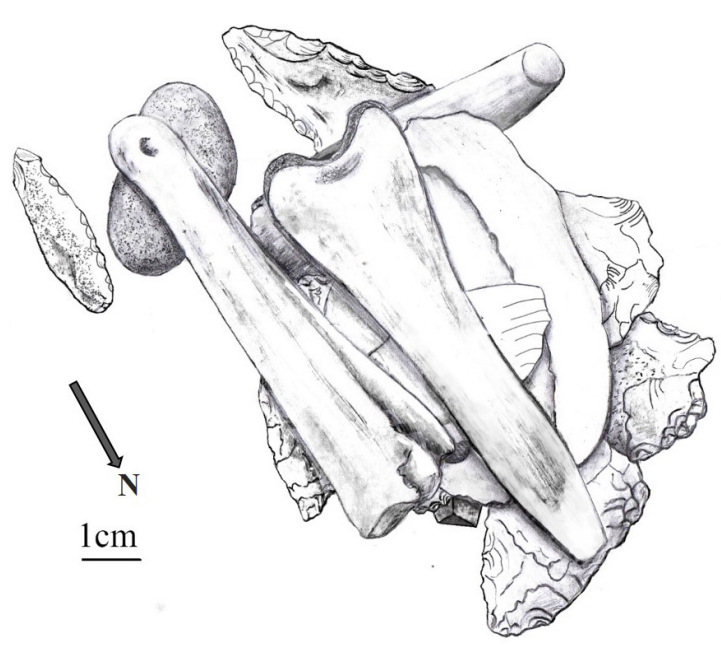

Figura 4. Representación gráfica de la posición original de cada uno de los elementos que componen el ajuar mortuorio de CLV2. Dibujo de Silvia E. Manuale.

Graphic representation of the original position of each of the CLV2 grave goods. Drawing by Silvia E. Manuale. 


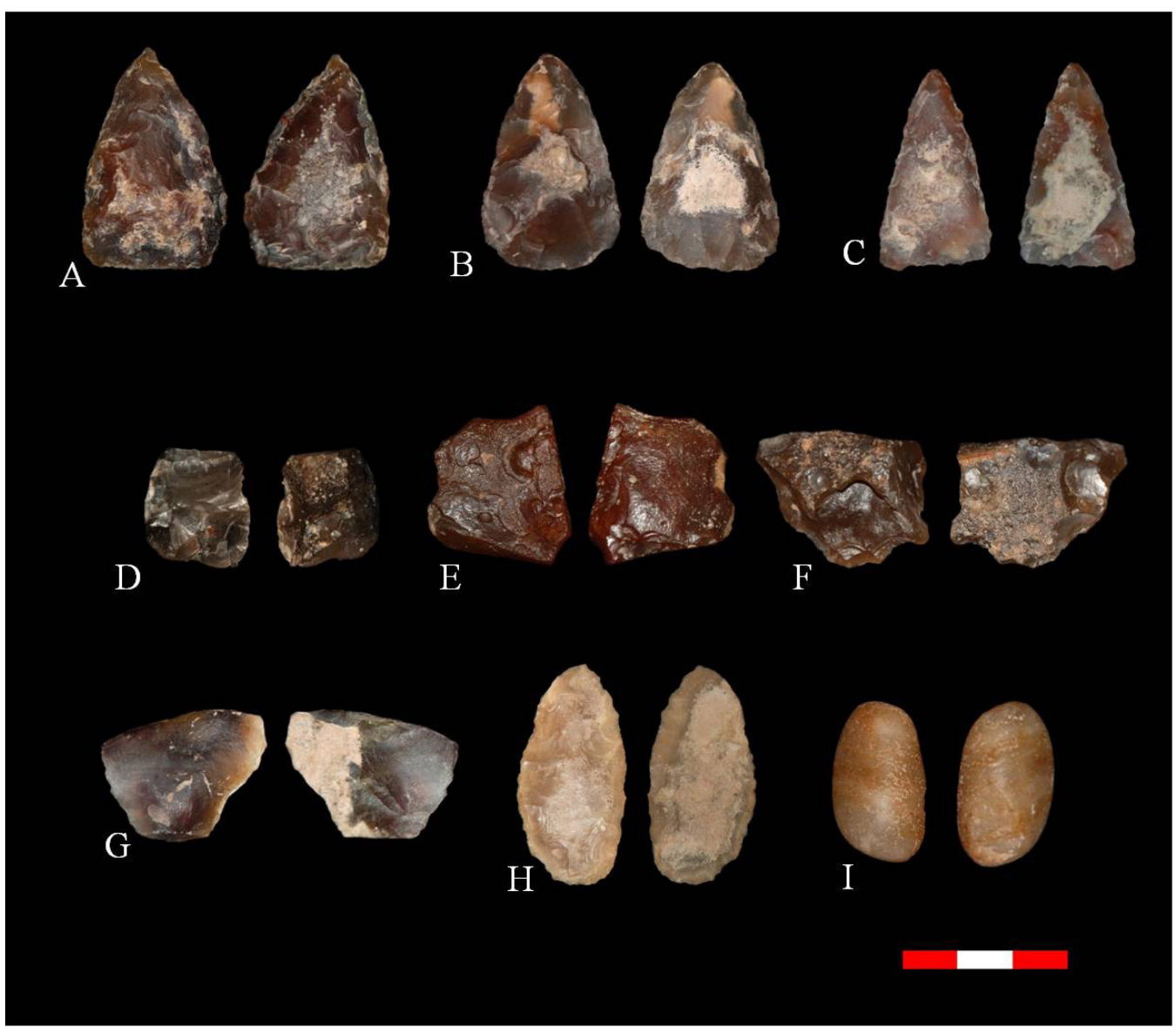

Figura 5. Artefactos líticos del ajuar mortuorio. Referencias: m: mapeo. (A) Punta de proyectil m56; (B) Punta de proyectil m59; (C) Punta de proyectil m64; (D) Núcleo m58; (E) Núcleo m60; (F) Núcleo m62; (G) Lasca m43; (H) Cuchillo m57; (I) Rodado m63.

Lithic grave goods. Reference: m: mapping. (A) Projectile point m56; (B) Projectile point m59; (C) Projectile point m64; (D) Core m58; (E) Core m60; (F) Core m62; (G) Flake m43; (H) Knife m57; (I) Pebble m63.

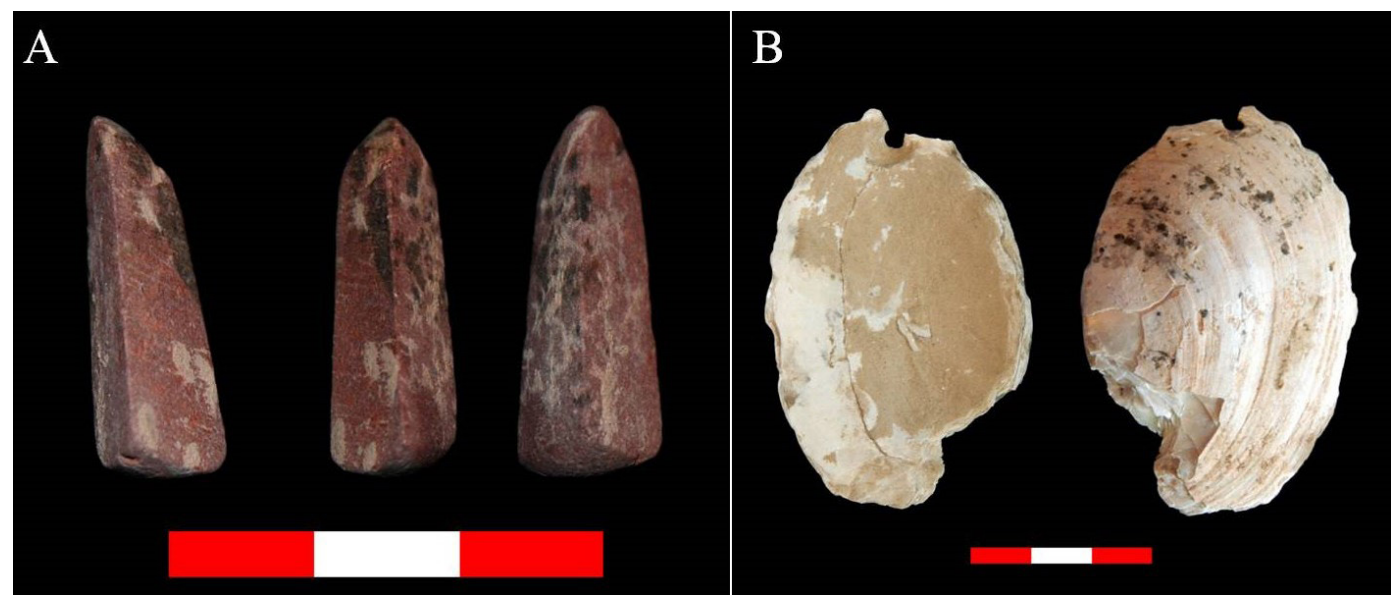

Figura 6. (A) Crayón de hematita de sección triangular. En la imagen se observan las tres caras y marcas de uso; (B) Adorno confeccionado en valva de Diplodon.

(A) Triangular section of hematite crayon. The image shows the three faces and traces of use; (B) Pendant made from a Diplodon shell. 
pirámide trunca. Dos de ellas presentan un alisado, casi pulido, con probable endurecimiento por acción de calor en todas sus caras, pero no se observaron huellas de manufactura (Figura 7 A, m41 a-d y m61 a-d). En ambos casos el extremo es romo, formando una plataforma levemente cóncava (Figura 7 B y C). El tercer ejemplar está levemente modificado, a la altura de los cóndilos y presenta huellas de manufactura (Figura 7 A, m40 a-d). En ninguno de ellos se ha podido determinar su funcionalidad dado que no presentan huellas de uso en observación macroscópica, con lupa binocular y microscopio digital.

\section{Discusión}

\section{Prácticas mortuorias del Holoceno Medio en la Región Pampeana}

A nivel regional se han registrado 15 sitios del Holoceno Medio con evidencia bioarqueológica, y en todos los casos la modalidad de inhumación es primaria. Solo cinco de estos sitios presentan ajuares mortuorios: Arroyo Seco 2, Necochea, Arroyo del Moro, ubicados en Pampa Oriental; Casa de Piedra 1 y CLV2, ubicados en Pampa Occidental (Tabla 3). En el sitio Arroyo Seco 2 se registró la presencia de 52 individuos inhumados entre ca. 7800 y 4400 años AP. Solo 12 de estos presentan ajuar, entre ellos hay ocho subadultos de sexo indeterminado y cuatro adultos (dos masculinos y dos femeninos). Se contabilizaron cerca de 550 objetos de adorno, entre los cuales se identificaron caninos de cánidos perforados, cuentas de valvas semiesféricas, cuentas de valvas discoidales y placas cuadrangulares perforadas sobre valvas (Laporte 2014; Politis et al. 2014; Scabuzzo y Politis 2010, 2019). En el sitio Necochea, se recuperaron cinco individuos (cuatro adultos y un subadulto), uno de los cuales registra la presencia de cuentas circulares de valva y "anzuelos" de hueso asociados, con una antigüedad de ca. 7000 años (Ameghino 1910; Bonomo et al. 2013). Con una cronología similar, en Arroyo del Moro se hallaron piedras con pigmentos rojos y blancos acompañando la inhumación de uno de los dos individuos adultos de sexo femenino encontrados por F. Ameghino (Ameghino 1910; Bonomo et al. 2013). En síntesis, en Pampa Oriental presentan ajuar tanto individuos adultos como subadultos, mientras que los dos casos registrados en Pampa Occidental son adultos masculinos.
CLV2 representa el segundo caso de enterratorio del Holoceno Medio registrado en Pampa Occidental. Tanto por su rango cronológico como por otros aspectos es comparable al registrado por Gradin et al. (1984) en el sitio Casa de Piedra 1 (CP1), excavado por una de las autoras de este trabajo (MB, Tabla 4). El enterratorio de CP1 fue fechado contextualmente en $6080 \pm 120$ años AP, I-12.065 a partir de espículas de carbón recuperadas en una estructura de combustión ubicada levemente por encima del mismo. Gradin interpretó que el enterratorio correspondería a esa antigüedad pues observó indicios de cavado para su inhumación (Gradin et al. 1984). Posteriormente el fechado fue calibrado con $1 \sigma \mathrm{y}$ dio un rango de antigüedad entre 6795-7029 cal AP (Berón 2004). En cambio CLV2 fue fechado directamente a partir de un molar (Tabla 1).

Ambos casos son entierros primarios simples de individuos masculinos adultos, de estatura mediana. Habrían estado contenidos en algún tipo de envoltorio, que en el caso de CP1 podría haber sido un cuero pintando de rojo, dada la presencia de ocre en los sedimentos circundantes. No hay mayores indicios de ello para CLV2, salvo la flexión de los miembros. Ambos casos presentan complejos ajuares colocados a la altura del pecho, entre los brazos del individuo, seguramente contenidos en algún tipo de envoltorio o bolsa, dada la aglomeración de los objetos. También ambos contienen artefactos líticos que podría dar cuenta de alguna de las tareas desarrolladas por el individuo, ya sea la de tallador, cazador, o ambas. Entre las diferencias, se destaca en CLV2 la presencia de tres artefactos óseos confeccionados en falange de guanaco, de carácter excepcional y funcionalidad desconocida.

Artefactos óseos de cierta similitud han sido detectados en el norte bonaerense y en las sierras de Córdoba. En el sitio Hunter (Pampa Ondulada), con una cronología de $1990 \pm 40$ años ${ }^{14} \mathrm{C} \mathrm{AP}$, fueron halladas tres primeras falanges de guanaco sin fusionar, modificadas en las carillas de articulación (Acosta et al. 2020: Figura 4), que presentan gran similitud con las halladas en el ajuar de CLV2. Si bien fueron inicialmente consideradas como posibles retocadores (Loponte et al. 2010), en Acosta et al. (2020) su funcionalidad permanece en duda. Otras tres piezas museísticas del Valle de Punilla también confeccionadas sobre primeras falanges de camélido, presentan morfologías similares, aunque se encuentran completamente ahuecadas y su funcionalidad aún no ha sido definida (S. Pastor comp. pers. octubre 2020). Por otro lado, en 


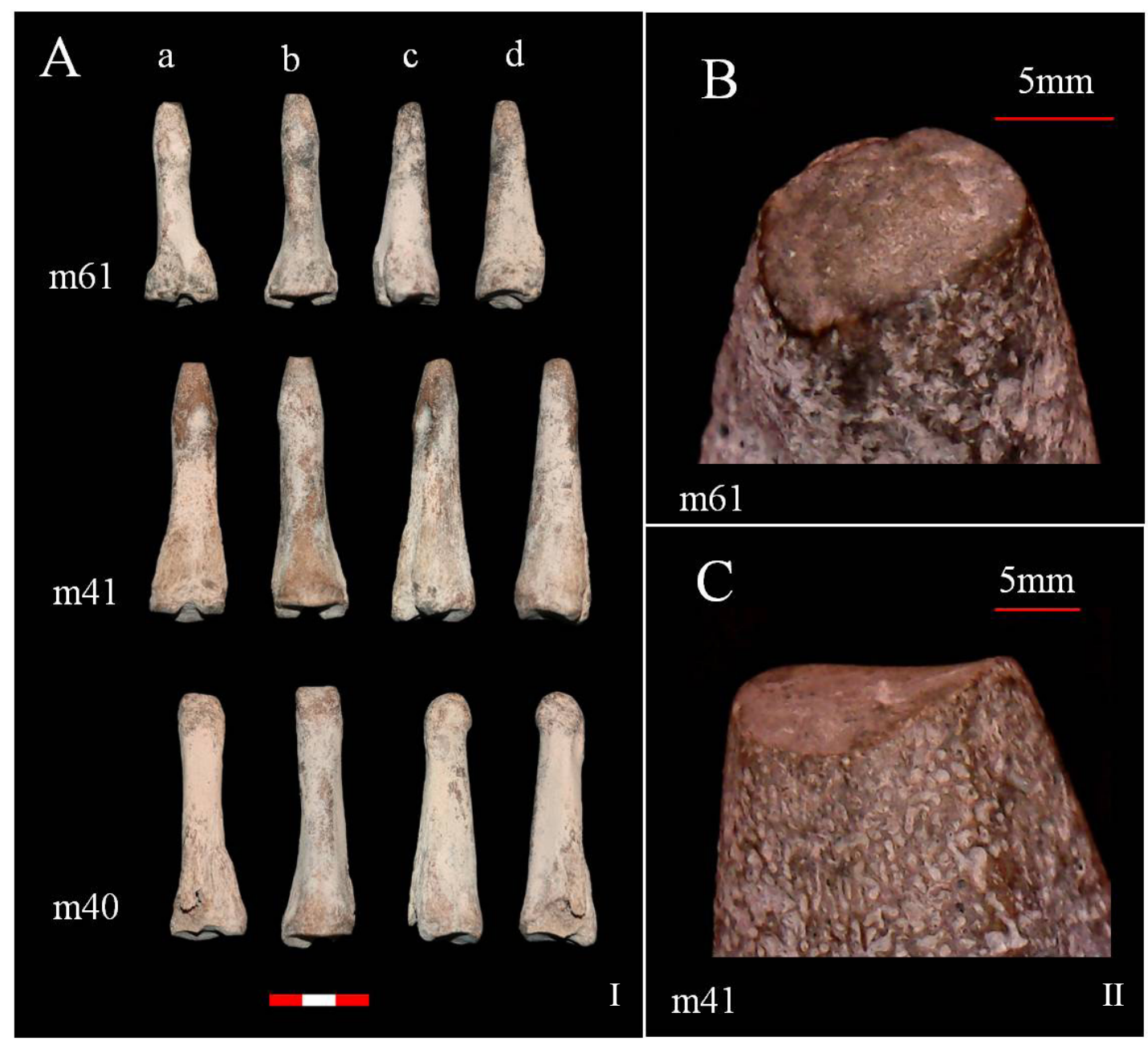

Figura 7. (I) Artefactos óseos confeccionados sobre primera falange de guanaco. (A) vista palmar; (B) vista ventral; (C y D) vista lateral/medial. (II) Detalle del extremo activo del artefacto m61. (III) Detalle del extremo activo del artefacto $\mathrm{m} 41$.

Bone artifacts made from the first guanaco phalanx. (A) palmar view; (B) ventral view; (C and D) lateral /medial view. (II) Detail of active end of the $m 61$ artifact. (III) Detail of active end of the $m 41$ artifact.

Sierras Centrales, se recuperaron "puntas embotantes" confeccionadas sobre falanges de camélidos en los sitios Ongamira (Schobinger 1959) e Intihuasi (González 1960), aunque no es posible establecer una analogía morfo-funcional entre ellas y las halladas en CLV2.

\section{La relevancia de CLV2 dentro de la problemática del Holoceno Medio en la DAS}

Al considerar la trayectoria social de las poblaciones en diferentes ambientes desérticos y semidesérticos de la DAS, a partir de la frecuencia de dataciones radiocarbónicas, se observan tanto hiatos como señales arqueológicas débiles para el Holoceno Medio, con diferentes rangos cronológicos según la zona. La validación de este proxie como un indicador demográfico dio lugar a debates sobre la continuidad y discontinuidad de la ocupación humana durante este periodo, tanto a escala regional como macro regional (Araujo et al. 2005; Durán y Mikkan 2009; Durán et al. 2016; Gil et al. 2005; Grosjean et al. 2007; Neme et al. 2011; Núñez et al. 1999, 2002; Núñez y Santoro 1988; Politis 2014; Yacobaccio y Morales 2005; entre otros). En el centro-oeste de Argentina, Pampa, Norpatagonia y centro-sur de Chile, se han evaluado diferentes interpretaciones y modelos asociados principalmente a cambios climáticos globales y locales, cambios en los patrones de asentamiento, 
Tabla 3. Sitios con restos humanos del Holoceno Medio de la región pampeana argentina.

Middle Holocene burial sites in the Argentine Pampean region.

\begin{tabular}{|c|c|c|c|c|c|c|c|}
\hline Sitio & Subregión & Microrregión & ${ }^{14} \mathrm{C}$ años AP & Código Lab. & Material & Ajuar & Referencias \\
\hline Laguna El Doce & $\begin{array}{l}\text { Pampa } \\
\text { Oriental }\end{array}$ & Norte & $8274 \pm 68$ & Arizona AA89915 & Diente & - & Ávila (2011) \\
\hline Meseta del Chocorí & $\begin{array}{l}\text { Pampa } \\
\text { Oriental }\end{array}$ & Interserrana & $7623 \pm 78$ & AA-90124 & Óseo & - & Bonomo et al. (2013) \\
\hline La Tigra & $\begin{array}{l}\text { Pampa } \\
\text { Oriental }\end{array}$ & Interserrana & $7270 \pm 60$ & CAMS-16173 & Óseo & - & Politis et al. (2011) \\
\hline Arroyo Chocorí & $\begin{array}{l}\text { Pampa } \\
\text { Oriental }\end{array}$ & Interserrana & $7010 \pm 60,6830 \pm 40$ & $\begin{array}{l}\text { CAMS-1659, Beta- } \\
223181\end{array}$ & Óseo & - & $\begin{array}{l}\text { Politis et al. (2011); } \\
\text { Bonomo et al. (2013) }\end{array}$ \\
\hline El Guanaco & $\begin{array}{l}\text { Pampa } \\
\text { Oriental }\end{array}$ & Interserrana & $8123 \pm 82$ & AA- 82710 & Óseo & - & $\begin{array}{l}\text { Flegenheimer et al. } \\
(2010)\end{array}$ \\
\hline Arroyo Seco 2 & $\begin{array}{l}\text { Pampa } \\
\text { Oriental }\end{array}$ & Interserrana & $\begin{array}{l}7043 \pm 82,6560 \pm 60 \\
6300 \pm 70,4793 \pm 69 \\
4487 \pm 45\end{array}$ & $\begin{array}{l}\text { AA-62517, LP-186, } \\
\text { AA-7966, AA-59506, } \\
\text { AA-67737 }\end{array}$ & Óseo & SI & Politis et al. (2014) \\
\hline Arroyo del Moro & $\begin{array}{l}\text { Pampa } \\
\text { Oriental }\end{array}$ & Interserrana & $6885 \pm 73,6220 \pm 40$ & $\begin{array}{l}\text { AA-90123, Beta- } \\
223187\end{array}$ & Óseo & SI & $\begin{array}{l}\text { Politis y Bonomo } \\
\text { (2011); Bonomo et al. } \\
(2013)\end{array}$ \\
\hline Monte Hermoso I & $\begin{array}{l}\text { Pampa } \\
\text { Oriental }\end{array}$ & Interserrana & $6606 \pm 79$ & AA-64619 & Óseo & - & Politis et al. (2009) \\
\hline Necochea & $\begin{array}{l}\text { Pampa } \\
\text { Oriental }\end{array}$ & Interserrana & $7162 \pm 74,7013 \pm 67$ & $\begin{array}{l}\text { AA-90125, AA- } \\
90122\end{array}$ & Óseo & SI & $\begin{array}{l}\text { Politis y Bonomo } \\
\text { (2011); Bonomo et al. } \\
(2013)\end{array}$ \\
\hline La Modesta & $\begin{array}{l}\text { Pampa } \\
\text { Oriental }\end{array}$ & $\begin{array}{l}\text { Cuenca inferior } \\
\text { del Río Colorado }\end{array}$ & $5904 \pm 37,5890 \pm 52$ & $\begin{array}{l}\text { AA-107619, AA- } \\
105416\end{array}$ & Óseo & - & $\begin{array}{l}\text { Martínez (2017); } \\
\text { Carden y Martínez } \\
\text { (2014); Stoessel } \\
(2015)\end{array}$ \\
\hline $\begin{array}{l}\text { Loma de Los } \\
\text { Morteros }\end{array}$ & $\begin{array}{l}\text { Pampa } \\
\text { Oriental }\end{array}$ & $\begin{array}{l}\text { Cuenca inferior } \\
\text { del Río Colorado }\end{array}$ & $4454 \pm 60$ & AA-101876 & Óseo & - & $\begin{array}{l}\text { Carden y Martínez } \\
\text { (2014); Stoessel } \\
(2015)\end{array}$ \\
\hline $\begin{array}{l}\text { Cantera de Rodados } \\
\text { Villalonga }\end{array}$ & $\begin{array}{l}\text { Pampa } \\
\text { Oriental }\end{array}$ & $\begin{array}{l}\text { Cuenca inferior } \\
\text { del Río Colorado }\end{array}$ & $\begin{array}{l}4889 \pm 58,4502 \pm 56 \\
4100 \pm 80\end{array}$ & $\begin{array}{l}\text { AA-91549, AA- } \\
\text { 91550, LP-2452 }\end{array}$ & Óseo & - & $\begin{array}{l}\text { G. Martínez et al. } \\
\text { (2012) }\end{array}$ \\
\hline Tres Bonetes 1 & $\begin{array}{l}\text { Pampa } \\
\text { Oriental } \\
\end{array}$ & $\begin{array}{l}\text { Cuenca inferior } \\
\text { del Río Colorado }\end{array}$ & $\begin{array}{l}5339 \pm 39,5188 \pm 40 \\
, 5182 \pm 46\end{array}$ & $\begin{array}{l}\text { AA-106788, AA- } \\
\text { 106786, AA-10678 }\end{array}$ & Óseo & - & Martínez (2017) \\
\hline CLV2 & $\begin{array}{l}\text { Pampa } \\
\text { Occidental }\end{array}$ & Oeste & $5160 \pm 20$ & UGAMS 38074 & Diente & SI & Este trabajo \\
\hline Casa de Piedra & $\begin{array}{l}\text { Pampa } \\
\text { Occidental }\end{array}$ & Oeste & $6080 \pm 120$ & Teledyne I-12.065 & Carbón & SI & Gradin et al. (1984) \\
\hline
\end{tabular}

aumento de las condiciones de aridez, degradación de los recursos y eventos catastróficos (Durán y Mikkan 2009; Durán et al. 2016; Gil et al. 2005; Méndez et al. 2015; Neme y Gil 2009; entre otros).

Para la provincia de Mendoza, se registra una baja señal arqueológica en el sector sur, con excepción de los valles intermedios de cordillera (Atuel y Salado) donde se recuperaron evidencias culturales datadas en ca. 5500 años AP (Neme y Gil 2008). Gil et al. (2005) plantean que la disminución del registro arqueológico durante este periodo, en comparación con el Holoceno Temprano, podría deberse al incremento de la aridización y la consecuente reducción de biomasa y fuentes de agua disponibles. Esto provocó cambios en la intensidad de ocupación, uso del espacio, movilidad y demografía de los grupos humanos que habitaron la región. Durán y Mikkan (2009) sostienen que los eventos volcánicos catastróficos acontecidos durante el Holoceno Medio provocaron alteraciones en los ecosistemas cordilleranos. El impacto posterior, sumado a la aridez del periodo, habría ocasionado una recuperación lenta del ambiente, transformando ciertos sectores en espacios inhabilitados para la ocupación humana durante largos periodos (Durán 1997, 2002; Durán et al. 2016). Para el norte de Mendoza se reconoce la existencia de un hiato cronológico que no sería producto de problemas de muestreo arqueológico ya que en la región se han detectado una gran variedad de sitios tempranos (Cortegoso 2005). A diferencia de ello, basado en la continuidad que observa en los sistemas de producción lítica en los sitios del Holoceno Medio del centro - norte de Mendoza, García (2005) considera que la escasa evidencia podría ser consecuencia de cambios en los patrones de asentamiento y/o de problemas de muestreo.

Para ambas vertientes de la cordillera, entre $29^{\circ}$ y $38^{\circ}$ LS, se ha propuesto que frente a un panorama ambiental de creciente aridez, los grupos humanos respondieron con una reorganización de los asentamientos y patrones de movilidad (Méndez et al. 2015, 2016; Neme y Gil 2009). Debido a que los ambientes cordilleranos de la vertiente andina occidental no presentan una merma de la señal arqueológica (Méndez et al. 2015, 2016) como en 
Tabla 4. Comparación entre los Entierros CLV2 y Casa de Piedra 1.

Comparison between CLV2 and Casa de Piedra 1 burials.

\begin{tabular}{|c|c|c|}
\hline & Casa de Piedra 1 & CLV2 \\
\hline Cronología radiocarbónica & $6080 \pm 120$ AP, Teledyne I-12.065 (carbón) & $5120 \pm 20$ AP, UGAMS 38074 (diente) \\
\hline Cronología cal AP $1 \Sigma$ & $6795-7029(\Sigma \pm 120)$ & $5909-5928(\Sigma \pm 20)$ \\
\hline Modalidad & Primario & Primario \\
\hline Posición & Semiflectada & Decúbito lateral derecho \\
\hline Orientación & SO-NE & $\mathrm{N}-\mathrm{S}$ \\
\hline Enfardamiento & SI & $?$ \\
\hline Estructura & Lecho de rocas para servir de cerco o fondo & Conjunto de piedra lajas por encima \\
\hline Sexo & Masculino & Masculino \\
\hline Edad & Adulto & Adulto \\
\hline Estatura & Mediana & Mediana \\
\hline \multirow{8}{*}{ Ajuar } & Dos puntas triangulares de sílice & Tres puntas triangulares de sílice \\
\hline & Tres cuchillos de sílice & Cuchillo de sílice \\
\hline & Preforma de sílice & Tres núcleos de sílice \\
\hline & - & Lasca de sílice \\
\hline & Gaimen & Guijarro natural \\
\hline & - & Crayón de ocre rojo \\
\hline & Dos fragmentos valva Diplodon & Ornamento sobre valva Diplodon \\
\hline & - & Tres artefactos óseos ( $1^{\circ}$ falange camélido) \\
\hline Ubicación ajuar & Sobre el pecho o entre los brazos & Entre los brazos, a la altura del pecho \\
\hline Ocre sobre huesos & SI & NO \\
\hline Fuente & Berón (2004), Gradín et al. (1984) & Este trabajo \\
\hline
\end{tabular}

la vertiente oriental (Neme y Gil 2009), se ha planteado, retomando la propuesta de Jackson (2002), la posibilidad que durante los momentos de mayor estrés ambiental, los grupos humanos se trasladaron estacionalmente entre ambas vertientes, complementando un uso anual integrado de la región andina.

Barberena et al. (2017) abordan esta problemática en una escala de análisis macro regional, comparando datos paleoecológicos y fechados radiocarbónicos disponibles para diferentes regiones de la franja cordillerana de la DAS. Luego de evaluar y descartar diferentes sesgos que podrían incidir en la disminución de la señal arqueológica, señalan que el registro arqueológico del Holoceno Medio a lo largo de esta porción de la DAS indicaría una merma demográfica a gran escala, a lo que se agrega una "contracción del rango" o del espacio ocupado por poblaciones humanas (Barberena et al. 2017 y referencias allí citadas).

La baja señal arqueológica registrada durante el Holoceno Medio no es un problema exclusivo del sector cordillerano de la DAS, sino que también ha sido identificada en otros sectores de Argentina. En la subregión Pampa Oriental, fueron propuestas distintas causas para explicar esta situación, como la ocurrencia de procesos de emigración y/o extinción local de poblaciones a partir de datos bioantropológicos (Barrientos y Pérez 2005); una disminución en la densidad poblacional pero con un poblamiento humano continuo (Martínez et al. 2015; Politis 1986, 2008); y/o una reorganización de las estrategias de asentamiento y movilidad (Martínez 1999; 2002). Politis (2014) contrastó el supuesto reemplazo poblacional propuesto por Barrientos y Pérez (2002) a partir de las dataciones obtenidas sobre restos humanos de Arroyo Seco 2 y otros sitios del sudeste de la provincia de Buenos Aires. Por el contrario, sostiene que los cambios poblacionales habrían sido graduales y producto de los procesos históricos y evolutivos de las poblaciones locales. Actualmente, el creciente número de sitios detectados, con cronologías del Holoceno Medio, tanto en la subregión Pampa Oriental como en el sector oriental de la DAS (área transicional pampeano-patagónica), 
estas secuencias, para obtener cronologías de este periodo a escala regional, como se consigna en diversas investigaciones (Bayón et al. 2010; Massigoge et al. 2014; Mazzanti et al. 2013; Politis et al. 2014).

Desdeeliniciodeestadiscusiónhace aproximadamente 20 años, el conocimiento arqueológico del Holoceno Medio se ha ido incrementando paulatinamente, con diferencias en cada región de estudio. Actualmente existe un registro de más de 70 sitios en dos ambientes diferentes: sector centromeridional de la DAS y Pampa Oriental (Figura 8). Los modelos de extinción y reemplazo poblacional mencionados antes, ya no se sostienen, sin embargo aún persisten hiatos o una señal arqueológica débil en algunos sectores como Norpatagonia, Pampa Occidental y sur de Cuyo.

\section{El Holoceno Medio en Pampa Occidental}

Este periodo está representado en la subregión Pampa Occidental por tres sitios: Casa de Piedra 1 (CP1), sitio 1 de la Localidad Tapera Moreira (STM1) y CLV2 de la Localidad Cerro de los Viejos. En el primer caso, se registraron fechados del Holoceno Medio en la base de las "Ocupaciones Inferiores" (7560 \pm 230 años AP) y en la cumbre de las "Ocupaciones Intermedias" (6080 \pm 120 años AP) (Gradin et al. 1984), mientras que en STM1

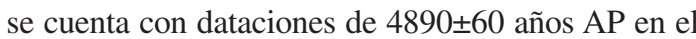
Componente Inferior (Berón 2004). Entre el fechado más reciente de $\mathrm{CP} 1$ y el comienzo de los asentamientos humanos en STM1, se registra un hiato de información de aproximadamente mil años, aunque CP1 presenta "Ocupaciones Superiores" que no fueron datadas y podrían cubrir parte de este lapso. Una situación similar, aunque con variantes locales en la cronología, ha sido identificada en la macro región (Berón 2015).

Como se mencionó, se han postulado numerosas causas para explicar la baja señal arqueológica del Holoceno Medio. Un motivo posible es el sesgo estratigráfico generado por la erosión de los estratos asociados a este periodo. En Pampa Occidental no se han desarrollado estudios geoarqueológicos detallados, pero se asume que eventos erosivos de gran escala barrieron gran parte de los estratos del cuaternario (Mehl et al. 2018; Melchor y Llambías 2004; Zárate y Tripaldi 2012). También se ha propuesto que, en caso de estar presentes, se encontrarían cubiertos por varios metros de sedimentos eólicos (Favier Dubois et al. 2017). Los cambios climáticos que afectaron la planicie Chaco-pampeana durante el Holoceno Tardío produjeron grandes eventos de erosión, pero también la depositación de un extenso manto de limo y arena (Iriondo 1990; Iriondo y García 1993; Schäbitz 2003). Debido a ello, en los sitios mencionados, las evidencias asociadas al Holoceno Medio se ubican a más de un metro de profundidad (Berón 2004; Gradin et al. 1984). Esto sugiere un posible sesgo en las investigaciones, ya que excepto en lugares de barrancas, cañadones u hoyadas de deflación, la señal arqueológica de este periodo es muy difícil de detectar. En el caso de las hoyadas también se debe tener en cuenta que la propia dinámica de los médanos fomenta los sesgos tafonómicos y la generación de palimpsestos (Martínez y Martínez 2011).

En relación con la ocurrencia de eventos catastróficos como el vulcanismo (Durán 1997; Durán y Mikkan 2009, Durán et al. 2016), en los niveles más profundos de la secuencia estratigráfica de STM1, los cuales son arqueológicamente estériles, se registra una concentración de cenizas volcánicas y la presencia de grandes cantidades de fitolitos articulados en fragmentos

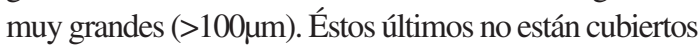
por material orgánico y podrían ser el producto de la calcinación generada por el contacto con las cenizas (Berón 2015). Ambos datos (presencia de ceniza y muerte de la flora) sugieren que algún evento volcánico potente ocurrió antes de que el sitio fuera ocupado. Es posible que un evento de estas características haya sido una de las causas que produjo la discontinuidad mencionada, entre las ocupaciones de Casa de Piedra y las de este nuevo ambiente de STM1 (Berón 1997, 2004, 2015). Sin embargo se requieren análisis químicos específicos de los sedimentos muestreados para evaluar el grado de impacto y la magnitud de la erupción.

\section{La dimensión social de los ecorrefugios}

Otras causas de discontinuidad señaladas para el periodo son de índole social y se vinculan con la estructura y organización de los grupos cazadoresrecolectores. En ambientes semidesérticos como los que presenta el sur pampeano, la densidad de población es generalmente baja (Veth 1993) y se agrupa en torno a lugares destacados, ambientes acuáticos o nodos en donde los recursos críticos, como el agua potable, presentan una mayor abundancia y disponibilidad (Berón 1994, 2016; Miotti 2006). Esto puede implicar la presencia de amplios espacios con una baja densidad arqueológica y su concentración en aquellos sectores donde las condiciones de habitabilidad fueron más propicias (Berón et al. 2017). Durante el Holoceno Medio, debido a los episodios de mayor aridez, esta situación pudo enfatizarse. De esta manera, se observa que los tres sitios identificados para este periodo se ubican en espacios con fuentes 
refuerzan la propuesta de una ocupación humana continua durante este periodo en algunos sectores (Bayón et al. 2010; Favier Dubois 2013; Martínez 2017; Martínez y Flensborg 2018; Martínez et al. 2015; Mazzanti et al. 2015; Politis 2014).

Desde el punto de vista geoarqueológico se han identificado, como posibles causas de la disminución de la señal arqueológica, sesgos estratigráficos relacionados a las bajas tasas de sedimentación, procesos erosivos que dan lugar a discordancias y/o desarrollo de suelos que provocan superposición de ocupaciones, generando palimpsestos (Favier Dubois 2006, 2015; Favier Dubois et al. 2017; Madrid et al. 2002). Por otro lado, Favier Dubois et al. (2017) señalan que los sitios emplazados en cuevas y aleros, médanos costeros y depósitos eólicos continentales podrían indicar el potencial de

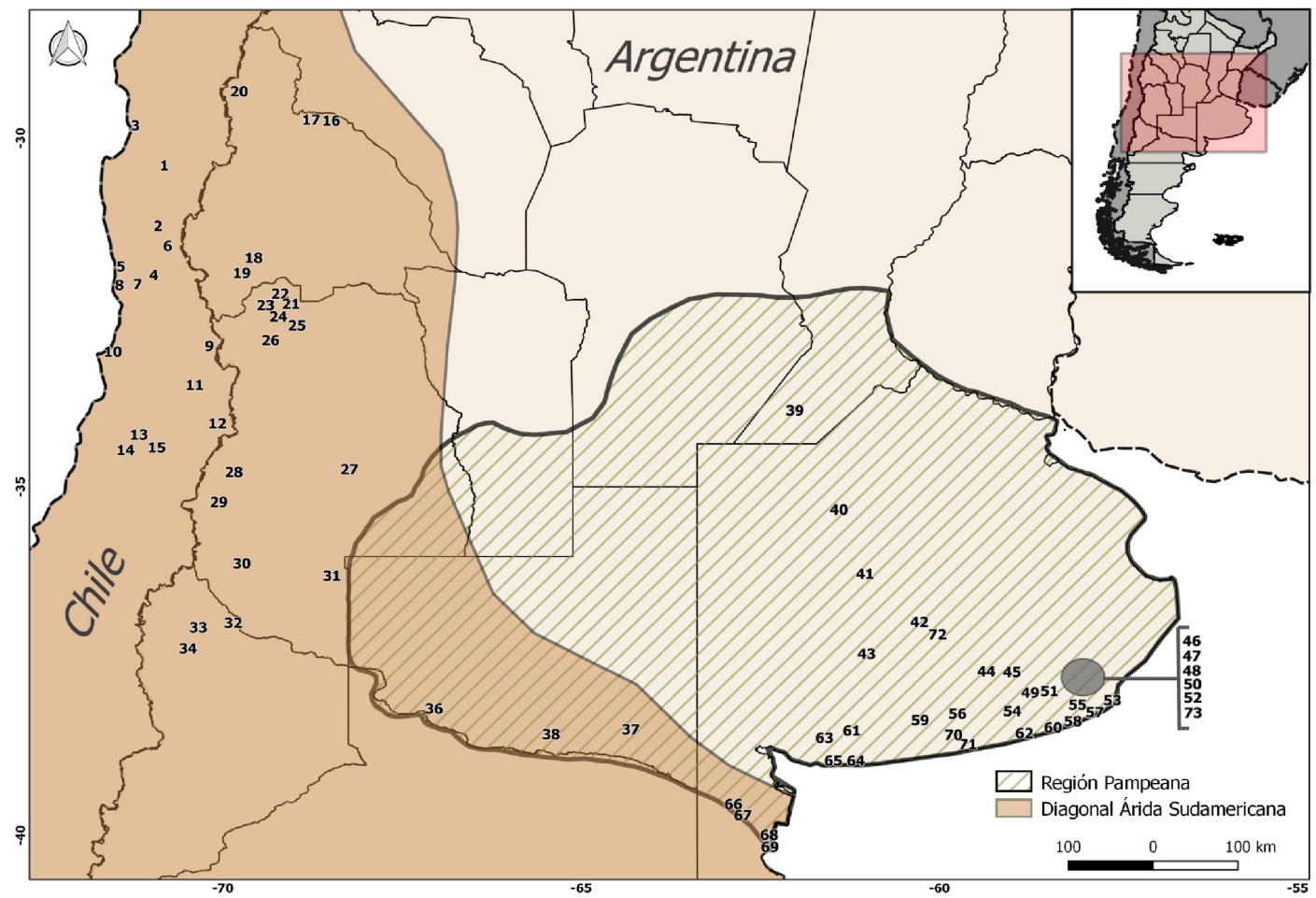

Figura 8. Localización de los sitios de la DAS y Pampa Oriental con cronologías correspondientes al Holoceno Medio (4200-8200 años AP sensu Walker et al. 2012). Referencias: 1-San Pedro Viejo de Pichasca ,2-Techo Negro, 3-Punta Teatinos, 4-El Mauro, 5-Los Vilos, 6-Alero Paulino Gonzalez, 7-Valiente, 8-Pichidangui LV531, 9-Piuquenes, 10-Punta Caraumilla 1, 11-El Manzano 1, 12-Holoceno, 13-Santa Inés, 14-Taguatagua 2, 15-Cuchipuy, 16-El Peñoncito, 17-Gualcamayo, 18-Los Morrillos Gruta 1 y 2, 19-Gruta del Chacaycillo, 20-ARQ-18, 21-El Tigre Alero 2, 22-Jaguel III, 23-Agua de la Tinaja, 24-Paso de los Paramillos, 25-Agua de la Cueva, 26-El Piedrón, 27-Gruta del Indio, 28-Arroyo Malo 3, 29-El Desecho 4, 30-Gruta el Manzano, 31-Cueva Delerma, 32-Cueva Huenul 1, 33-Aquihuecó, 34-Hermanos Lezcano, 35-La Susana 1, 36-Casa de Piedra 1, 37-CLV2, 38-Tapera Moreira 1, 39-Laguna El Doce, 40-Laguna de Los Pampas, 41-Laguna Cabeza de Buey 2, 42-El Puente, 43-Fortín Necochea, 44-Cantera Arroyo Diamante, 45-Picadero, 46-Cueva Tixi, 47-Alero El Mirador, 48-Abrigo Los Pinos, 49-Cerro La China Sitio 2, 50El Abra, 51-Lobería 1 Sitio 1, 52-Amalia Sitio 2, 53-Alfar, 54-Paso Otero 4, 55-Meseta del Chocorí, 56-Las Brusquillas 4, 57-La Tigra, 58-Arroyo Chocorí, 59-Arroyo Seco 2, 60-Arroyo del Moro, 61-Monte Hermoso I, 62-Necochea, 63-Paso Mayor 1, 64-Barrio Las Dunas, 65-La Olla, 66-La Modesta, 67-Loma de Los Morteros, 68-Cantera de Rodados Villalonga, 69-Tres Bonetes 1, 70-Las Toscas 5, 71-El Guanaco, 72-La Moderna, 73-Cueva Alí Mustafá.

Location of the DAS and Eastern Pampa sites with chronologies corresponding to the Middle Holocene (4200-8200 years BP sensu Walker et al. 2012). References: 1-San Pedro Viejo de Pichasca,2-Techo Negro, 3-Punta Teatinos, 4-El Mauro, 5-Los Vilos, 6-Alero Paulino Gonzalez, 7-Valiente, 8-Pichidangui LV531, 9-Piuquenes, 10-Punta Caraumilla 1, 11-El Manzano 1, 12-Holoceno, 13-Santa Inés, 14-Taguatagua 2, 15-Cuchipuy, 16-El Peñoncito, 17-Gualcamayo, 18-Los Morrillos Gruta 1 and 2, 19-Gruta del Chacaycillo, 20-ARQ-18, 21-El Tigre Alero 2, 22-Jaguel III, 23-Agua de la Tinaja, 24-Paso de los Paramillos, 25-Agua de la Cueva, 26-El Piedrón, 27-Gruta del Indio, 28-Arroyo Malo 3, 29-El Desecho 4, 30-Gruta el Manzano, 31-Cueva Delerma, 32-Cueva Huenul 1, 33-Aquihuecó, 34-Hermanos Lezcano, 35-La Susana 1, 36-Casa de Piedra 1, 37-CLV2, 38-Tapera Moreira 1, 39-Laguna El Doce, 40-Laguna de Los Pampas, 41-Laguna Cabeza de Buey 2, 42-El Puente, 43-Fortín Necochea, 44-Cantera Arroyo Diamante, 45-Picadero, 46-Cueva Tixi, 47-Alero El Mirador, 48-Abrigo Los Pinos, 49-Cerro La China Sitio 2, 50El Abra, 51-Lobería 1 Sitio 1, 52-Amalia Sitio 2, 53-Alfar, 54-Paso Otero 4, 55-Meseta del Chocorí, 56-Las Brusquillas 4, 57-La Tigra, 58-Arroyo Chocorí, 59-Arroyo Seco 2, 60-Arroyo del Moro, 61-Monte Hermoso I, 62-Necochea, 63-Paso Mayor 1, 64-Barrio Las Dunas, 65-La Olla, 66-La Modesta, 67-Loma de Los Morteros, 68-Cantera de Rodados Villalonga, 69-Tres Bonetes 1, 70-Las Toscas 5, 71-El Guanaco, 72-La Moderna, 73-Cueva Alí Mustafá. 
permanentes de agua, cuyas condiciones favorables habrían propiciado la ocupación por mayor número de personas, durante periodos prolongados (Berón 2015, 2016). En algunos casos, se trata de lugares ya utilizados previamente (p.ej., CP1), mientras que en otros (p.ej., STM1), a partir de estos momentos, se evidencia un uso continuo del espacio hasta momentos previos al contacto hispano-indígena. En el caso de CLV, se han registrado diferentes evidencias que señalan un uso diacrónico del lugar desde, al menos, el Holoceno Medio hasta tiempos históricos (Paez et al. 2020). En todos ellos las evidencias se conservan en depósitos tiempos esguardados por la topografía, como terrazas fluviales (CP1 y STM1) o entornos serranos (CLV).

En síntesis, la subregión comienza a poblarse durante el Holoceno Temprano en el área de Casa de Piedra y continúa durante el Holoceno Medio hasta, al menos ca. 6000 años AP. Luego hay un hiato en la información que abarca aproximadamente mil años, entre los ca. 6500 y $5500 \mathrm{cal} \mathrm{AP}$. El mismo podría vincularse con sesgos en la investigación, pero también con eventos catastróficos asociados al vulcanismo, cuyas consecuencias sobre el ambiente parecen estar evidenciadas en los niveles más profundos de STM1. Hacia los ca. 5000 años AP se registra el comienzo de la ocupación de dicho sitio. Las condiciones favorables de este ambiente, en cuanto a la disponibilidad de distintos tipos de recursos, entre ellos el agua, habrían servido como atractores para las poblaciones humanas que continuaron ocupándolo, casi ininterrumpidamente, hasta finales del Holoceno Tardío (Berón 2015, 2016; Berón et al. 2017). Al respecto, estudios geomorfológicos recientes analizaron las oscilaciones del nivel del mar y de las paleoredes fluviales a partir del último avance glaciario (UGM) en el área continental pampeana (Martínez et al. 2012; Melo et al. 2003). Melo et al. (2003) analizan la formación del estuario de Bahía Blanca y señalan que es el resultado de las interacciones de ambos dominios (marítimo y continental) ocurridas durante el Pleistoceno Tardío Holoceno. La presencia del Río Colorado y los valles y bajos alineados del sudeste pampeano indicarían un conjunto de formas vinculadas entre sí y al estuario, a partir de ca. 7.000 años AP. Martínez et al. (2012) ubican la distribución de los paleocauces del Colorado y señalan que uno de los paleovalles principales tuvo su recorrido a ca. $20 \mathrm{~km}$ al sur de CLV (Figura 9). Es posible que otro brazo de esta paleored de drenaje hubiera corrido a escasos $5 \mathrm{~km}$ al norte de CLV, tomando como referencia la depresión o bajo sin salida conocida como Laguna Blanca Grande. En este contexto el Cerro de los Viejos habría constituido un ecorrefugio adecuado para la colonización inicial de este ambiente, e incluso para la inhumación de algunos de sus pioneros.

En términos de Miotti (2006) el concepto de ambientes acuáticos, que equiparamos al de ecorrefugio, incluye una variada gama de paisajes de cuencas (surgentes, acuíferos, lagunas, lagos, arroyos, ríos, estuarios y pantanos):

son aquellos sectores que concentran la mayor variedad y abundancia biológica, mientras que las zonas de divisorias de cuencas son las que dispersan y separan esta variedad. Por esta razón, las chances de hallar una biodiversidad y abundancias taxonómicas mayores en los yacimientos arqueológicos y paleontológicos de cuencas es mucho mayor que en las zonas de divisorias [y] (...) son buenos indicadores para ampliar la exploración de nuevos territorios hacia el interior de los continentes ya que, por un lado contienen los recursos principales para la alimentación y por otro, estas cuencas son otras rutas seguras para los desplazamientos sin perder de vista el recurso crítico (Miotti 2006:159).

Tomando como referencia la propuesta de Miotti (2006), retomado en Prates y Bonomo (2017) y los estudios realizados por Melo et al. (2003) y Martínez et al. (2012), se propone para este sector de la Pampa Occidental una exploración lenta y discontinua que utilizaría como principales ejes a las cuencas hídricas de la vertiente Atlántica y sus tributarios, algunos actualmente inactivos. En el caso de CLV, entre los 7000 y 5000 años, las cuencas de transitabilidad fueron de distinto rango: vías principales de ingreso a la zona continental como el Río Colorado y vías secundarias como el sistema de drenaje constituido por los paleocauces de la cuenca del Colorado, que conectaban a su vez con la otra cuenca principal del Atuel-Salado-Chadileuvú-Curacó.

\section{Conclusiones}

A nivel macro regional, los datos presentados aportan nueva información sobre la presencia humana durante el Holoceno Medio, en el sector centro-meridional de la DAS y la región pampeana. Sin embargo, en términos generales, aún persiste una señal arqueológica baja o 

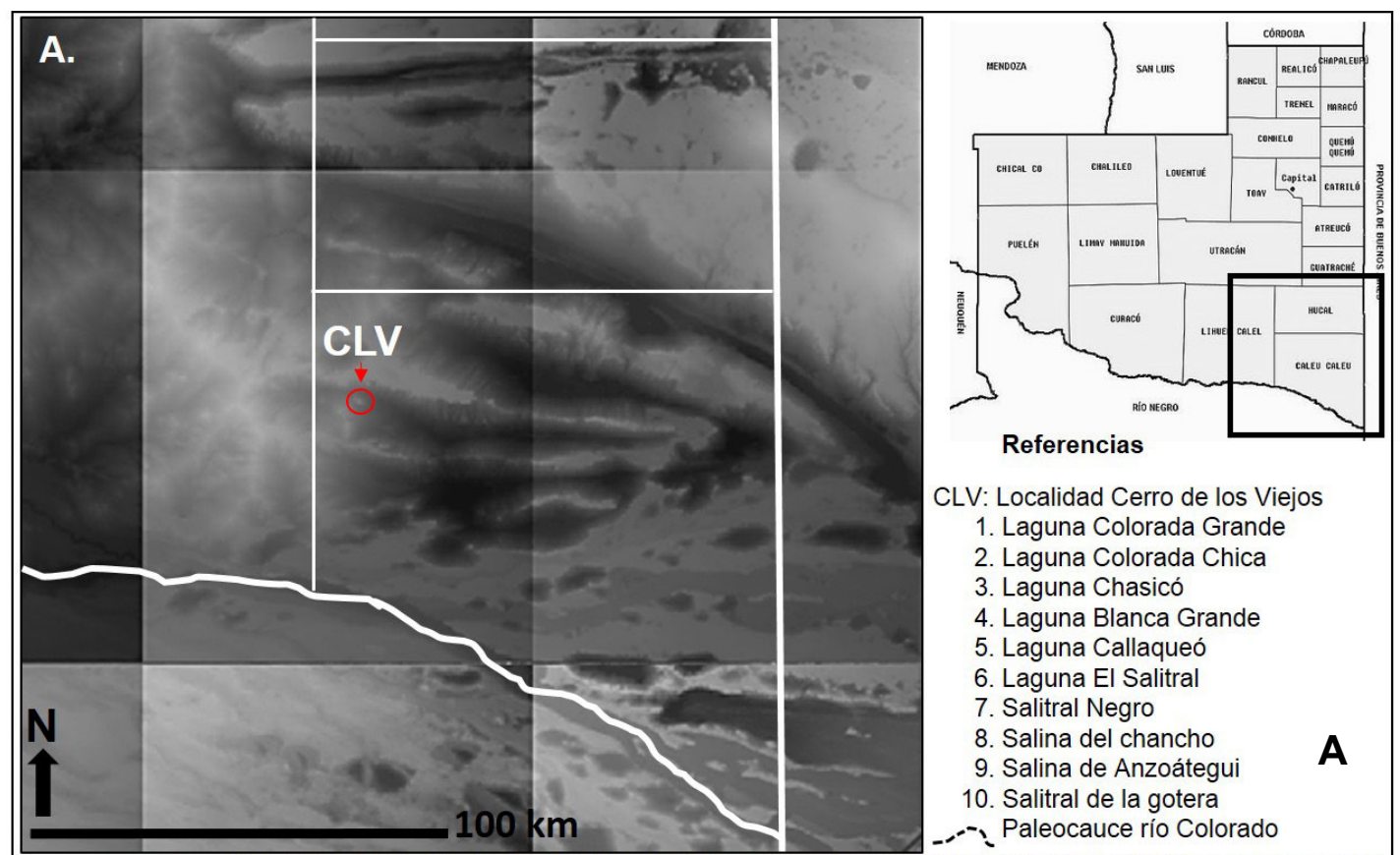

CLV: Localidad Cerro de los Viejos

1. Laguna Colorada Grande

2. Laguna Colorada Chica

3. Laguna Chasicó

4. Laguna Blanca Grande

5. Laguna Callaqueó

6. Laguna El Salitral

7. Salitral Negro

8. Salina del chancho

9. Salina de Anzoátegui

10. Salitral de la gotera

.-. Paleocauce río Colorado

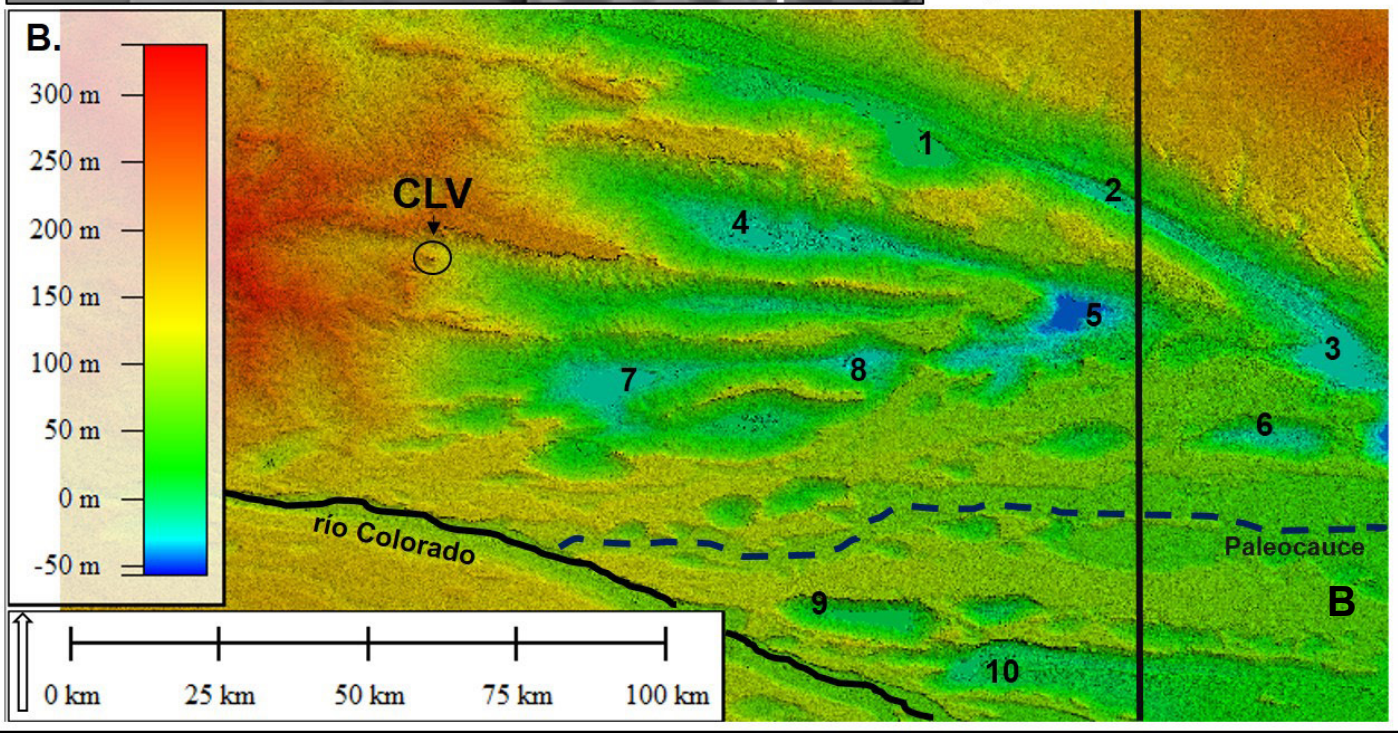

Figura 9. Ubicación de CLV y distribución de los bajos sin salida sobre: A- imagen LANDSAT (USGS) y B- modelo digital de elevación (SRTM), procesadas con Global Mapper v.22.

CLV location and distribution of the closed basins A- LANDSAT image (USGS) and B-digital elevation model (SRTM), processed using Global Mapper v.22. 
elusiva entre ca. 8000 y $6000 \mathrm{cal}$. AP que podría indicar un decrecimiento de la actividad humana durante la fase de máxima aridez del Holoceno Medio (Barberena et al. 2017; Méndez et al. 2015, 2016; Neme y Gil 2009).

A escala subregional (Pampa Occidental), CLV2 es el segundo sitio de mayor antigüedad con fechados absolutos, tomando en cuenta CP1 y STM1. Si bien la información es aún escasa, se observan algunas tendencias en las modalidades de entierro y en la estructura del registro arqueológico para este periodo. Además, ambos enterratorios (CLV2 y CP1) fueron recuperados en cercanías de cursos fluviales o próximos a antiguos paleocauces o paleoredes de drenaje. Esto refuerza la propuesta de la colonización inicial en ambientes acuáticos, de acuerdo al planteo de Miotti (2006). En este escenario, algunos espacios concentradores de recursos tuvieron un rol nodular en términos de permanencia demográfica. Estos lugares actuaron como ecorrefugios que permitieron hacer frente a los riesgos que prevalecieron durante situaciones de estrés ambiental. Como mencionan Miotti et al. (2015), a medida que los ecorrefugios se incorporan al espacio de vida de los grupos humanos, se caracterizan por presentar materialidades que representan marcadores, equipamiento o acondicionamientos, que corresponderían a diferentes temporalidades y que se relacionan con prácticas sociales y culturales diferentes, es decir, que representan a grupos sociales variados en tiempo y espacio que confluyen en estas áreas. En el caso de la localidad Cerro de los Viejos, además de la estructura de entierro discutida en este trabajo, los marcadores que señalan un continuum ocupacional, estarían representados por un mortero múltiple de uso transgeneracional y, para momentos históricos, por el conjunto de represas y esclusas que permitieron el manejo del recurso agua, cuya construcción también pudo ser consecuencia de eventos sociales distanciados en el tiempo.

Agradecimientos: Las investigaciones se realizaron en el marco de los proyectos ASETUR "Puesta en valor del sitio Arqueológico Cerro de los Viejos (Cuchillo Có, La Pampa)", dirigido por la Dirección de Patrimonio de la Secretaría de Cultura de la provincia de La Pampa; PIP 0679 y UBACyT 540 BA. Agradecemos a los pobladores de Cuchillo Có, la Municipalidad de La Adela y a la familia Iturrioz por su hospitalidad en cada visita al Cerro. Nuestra gratitud a los siguientes colegas que desinteresadamente han colaborado de diferentes maneras: Guido Pastorino, Mariano Bonomo, Natacha Buc, Sebastián Pastor, Vivian Scheisohn, Dolores Elkin, Ignacio Roca, Jerónimo Angueyra, Daniel Rafuse y finalmente a Silvia Manuale (IDECU, CONICET-UBA), quien realizó el dibujo que reconstruye tridimensionalmente el ajuar. A los evaluadores anónimos que con sus sugerencias y observaciones nos permitieron mejorar el manuscrito.

\section{Referencias Citadas}

Acosta, A.A., N. Buc y D.M. Loponte 2020. Tecnología ósea de los grupos cazadores-recolectores de la Pampa Ondulada (provincia de Buenos Aires). Revista del Museo de Antropología 13 (2):79-92.

Aguirre, M.L. y R.C. Whatley 1995. Late Quaternary marginal marine deposits and palaeonvironments from northeastern Buenos Aires Province, Argentina: A review. Quaternary Science Reviews 14:223-254.

Ambrose, S. 1993. Isotopic analysis of paleodiets: methodological and interpretive considerations. En Investigations of Ancient Human Tissue, editado por M. Sandford, pp. 59-129. Gordon and Breach Science, Langhome.

Ameghino, F. 1910. Descubrimiento de dos esqueletos humanos fósiles en el pampeano inferior del Moro. Separata del XVII Congreso Científico Internacional Americano. Imprenta J. Alsina, Buenos Aires.

Aramayo, S.A., B. Gutiérrez de Téllez y R.A. Schillizzi 2005. Sedimentologic and Palaeontologic studies of the southeast coast of Buenos Aires province, Argentina: a late PleistoceneHolocene paleoenvironmental reconstruction. Journal of South America Earth Science 20:65-71.
Araujo, A.G., L.B. Pilo, W.A. Neves y J.P. Atui 2005. Human occupation and paleoenvironments in South America: expanding the notion of an "Archaic Gap". Revista do Museu de Arqueologia e Etnologia 15-16:3-35.

Ávila, J.D. 2011. Resultados de los fechados radiocarbónicos del sitio Laguna El Doce, Departamento General López, Provincia de Santa Fe. Relaciones XXXVI:337-343.

Barberena, R., C. Méndez y M.E. De Porras 2017. Zooming out from archaeological discontinuities: The meaning of midHolocene temporal troughs in South American deserts. Journal of Anthropological Archaeology 46:68-81.

Barberena, R., M. Berón y L. Luna 2018. Isótopos estables en el sitio Chenque I: paleodieta y procedencia geográfica. En El sitio Chenque I. Un Cementerio Prehispánico en la Pampa Occidental. Estilo de Vida e Interacciones Culturales de Cazadores-Recolectores del Cono Sur Americano, editado por M. Berón, pp. 367-395. Sociedad Argentina de Antropología, Buenos Aires.

Barrientos, G. y S.I. Pérez 2002. La dinámica del poblamiento humano del Sudeste de la Región Pampeana durante el Holoceno. Intersecciones en Antropología 3:41-54. 
Barrientos, G. y S.I. Pérez 2005. Was there a population replacement during the mid-Holocene in the southeastern Pampas of Argentina? Archaeological evidence and Paleoecological basis. Quaternary International 132:95-105.

Bastourre, M.L. y G. Salazar Siciliano 2012. Análisis arqueofaunístico de la localidad Tapera Moreira (departamento de Lihué Calel, provincia de La Pampa). Intersecciones en Antropología 13:269-280.

Bayón, C., A. Pupio, R. Frontini, R. Vecchi y C. Scabuzzo 2010. Localidad arqueológica Paso Mayor: nuevos estudios 40 años después. Intersecciones en Antropología 11:115-128.

Berón, M. 1994. El recurso y el método. Estrategias de movilidad y asentamiento en la Subregión Pampa Seca. Arqueología 4:213-234.

Berón, M. 1997. Cronología radiocarbónica de eventos culturales y algo más... Localidad Tapera Moreira, Área del Curacó, La Pampa, Argentina. Cuadernos del Instituto Nacional de Antropología 16:261-282.

Berón, M. 2004. Dinámica Poblacional y Estrategias de Subsistencia de Poblaciones Prehispánicas de la Cuenca AtuelSalado-Chadileuvú-Curacó, Provincia de La Pampa. Tesis para optar al grado de doctora en arqueología. Facultad de Filosofía y Letras, Universidad de Buenos Aires, Buenos Aires.

Berón, M. 2015. Chronological distribution and disturbance factors to evaluate population dynamics in Western Pampas, Argentina. Quaternary International 356:74-88.

Berón, M. 2016. Dunes, hills, waterholes, and saltpeter beds: Attractors for human populations in western Pampa, Argentina. Quaternary International 422:163-173.

Berón, M. 2018. Elementos de adorno, ajuares y acompañamientos funerarios del sitio Chenque I. En El Sitio Chenque I. Un Cementerio Prehispánico en la Pampa Occidental. Estilo de Vida e Interacciones Culturales de Cazadores-Recolectores del Cono Sur Americano, editado por M. Berón, pp. 285-325. Sociedad Argentina de Antropología, Buenos Aires.

Berón, M., M. Carrera Aizpitarte y F. Paez 2015. Arqueología en el área de Valles Transversales (provincia de La Pampa, Argentina). Caracterización y tendencias de los conjuntos arqueológicos. Implicancias sociales en la construcción del paisaje. Relaciones de la Sociedad Argentina de Antropología XL (2):549-587.

Berón, M., A. Di Biase, G. Musaubach y F. Paez 2017. Enclaves y espacios internodales en la dinámica de poblaciones en el Wall-Mapu: aportes desde la arqueología pampeana. Estudios Atacameños (56):253-272.

Berón, M., L. Luna y R. Barberena 2009. Isotopic archaeology in the western Pampas (Argentina): preliminary results and perspectives. International Journal of Osteoarchaeology 19 (2):250-265.

Berón, M., L. Luna y R. Barberena 2013. Isótopos de oxígeno en restos humanos del sitio Chenque I: primeros resultados sobre procedencia geográfica de individuos. En Tendencias Teórico-Metodológicas y Casos de Estudio en la Arqueología de Patagonia, compilado por A.F. Zangrando, R. Barberena, A. Gil, G. Neme, M. Giardina, L. Luna, C. Otaola, S. Paulides, L. Salgán y A. Tivoli, pp. 27-38. Museo de Historia Natural, San Rafael, Mendoza.
Berón, M., F. Paez y M. Carrera Aizpitarte 2020. Ecorefugios pampeanos. Ayer y hoy. Revista Rastrilladas 3:12-17.

Bonadonna, F., G. Leone y G. Zanchetta 1995. Composición isotópica de los fósiles de gasterópodos continentales de la Provincia de Buenos Aires. Indicaciones Paleoclimáticas. En Evolución Biológica y Climática de la Región Pampeana durante los últimos cinco millones de años. Un Ensayo de Correlación con el Mediterráneo Occidental, editado por M.T. Alberdi, G. Leone y E. Tonni, pp. 77-104. Museo Nacional de Ciencias Naturales, CSIC, Madrid.

Bonomo, M., C. Scabuzzo y C. Leon 2013. Cronología y dieta en la costa atlántica pampeana, Argentina. Intersecciones en Antropología 14:123-136.

Borel, C.M., M.V. Bianchinotti y M.E. Quattrocchio 2001. Palinomorfos fúngicos del Pleistoceno-Holoceno en el valle del Arroyo Chasicó, provincia de Buenos Aires, Argentina. Polen 11:21-37.

Borrero, L. 1989-1990. Evolución cultural divergente en la Patagonia Austral. Anales del Instituto de la Patagonia (Serie Ciencias Sociales) 19:133-139.

Bruniard, E.D. 1982. La diagonal árida argentina: un límite climático real. Revista Geográfica del Instituto Panamericano 95:5-19.

Cabrera, A. 1960. Catálogo de los mamíferos de América del Sur. Revista del Museo Argentino de Ciencias Naturales B. Rivadavia (Zoología) 4 (1):309-732.

Carden, N. y G. Martínez 2014. Diseños fragmentados. Circulación social de imágenes sobre cáscaras de huevo de Rheidae en Pampa y Norpatagonia. Boletín del Museo Chileno de Arte Precolombino 19 (2):55-75.

Cioccale, M. 1999. Climatic fluctuations in the Central Region of Argentina in the last 1000 years. Quaternary International 62:35-47.

Clark, J.A. y A.L. Bloom 1978. Hydro-isostasy and Holocene emergence of South America. International Symposium on Coastal Evolution, Proceedings pp. 41-60. São Paulo.

Codignotto, J.O., R.R. Kokot y S.C. Marcomini 1992. Neotectonism and Sea-Level Changes in the Coastal Zone of Argentina. Journal of Coastal Research 8:125-133.

Cordini, R. 1967. Reservas Salinas de Argentina. Secretaría de Estado de Energía y Minería. Anales 13. Ministerio de Economía y Trabajo. Instituto Nacional de Geología y Minería, Buenos Aires.

Cortegoso, V. 2005. Mid-Holocene hunters in the Andes Mountains: environment, resources and technological strategies. Quaternary International 132:71-80.

Daus, F. 1959. Fisonomía Regional de la Argentina. Ed. Nova, Buenos Aires.

De Jong, C. y G. Cordero 2016. El malón en contrapunto: dinámicas de la diplomacia, el comercio y la guerra en la Frontera Sur (s. XVIII y XIX). En Los Saqueos en la Historia Argentina. Variaciones de una Acción Colectiva, compilado por G. Di Meglio y S. Serulnikov. Siglo XXI, Buenos Aires.

De la Sota, E.R. 1985. Las pteridofitas de la provincia de La Pampa, Argentina. Revista de la Facultad de Agronomía U. N. La Pampa 1 (1-2):23-34. 
Difrieri, H. 1958. Las regiones naturales. La Argentina. Suma de Geografía. Tomo 1. Editorial Peuser, Buenos Aires.

Durán, V. 1997. Cazadores-recolectores del Holoceno Medio en la Quebrada de La Manga (Luján de Cuyo, Mendoza). Revista de Estudios Regionales 17:7-48.

Durán, V. 2002. Nuevas consideraciones sobre la problemática arqueológica del valle del río Grande (Malargüe, Mendoza). En Entre Montañas y Desiertos: Arqueología del Sur de Mendoza, editado por A. Gil y G. Neme, pp. 85-102. Sociedad Argentina de Antropología, Buenos Aires.

Durán, V. y R. Mikkan 2009. Impacto del volcanismo holocénico sobre el poblamiento humano del sur de Mendoza (Argentina). Intersecciones en Antropología 10:295-310.

Durán, V., D. Winocur, C. Stern, R. Garvey, R. Barberena, J.L. Peña Monné y A. Benítez 2016. Impacto del volcanismo y glaciarismo holocénicos en el poblamiento humano de la cordillera sur de Mendoza (Argentina): una perspectiva geoarqueológica. Intersecciones en Antropología 17 (supl.2):33-46.

Erlandson, J.M. 2001. The Archaeology of Aquatic Adaptations: Paradigms for a New Millennium. Journal of an Archaeological Research 9 (4):287-350.

Favier Dubois, C. 2006. Dinámica fluvial, paleoambientes y ocupaciones humanas en la localidad arqueológica Paso Otero, río Quequén Grande, provincia de Buenos Aires. Intersecciones en Antropología 7:109-127.

Favier Dubois, C. 2013. Hacia una cronología del uso del espacio en la costa norte del Golfo San Matías (Río Negro, Argentina): Sesgos geológicos e indicadores temporales. En Tendencias Teórico Metodológicas y Casos de Estudio en la Arqueología de Patagonia, editado por F. Zangrando, R. Barberena, A. Gil, G. Neme, M. Giardina, L. Luna, C. Otaola, L. Paulides, L. Salgán y A. Tívoli, pp. 87-96. Museo de Historia Natural de San Rafael, Sociedad Argentina de Antropología. Instituto Nacional de Antropología y Pensamiento Latinoamericano y Secretaría de Cultura, Buenos Aires.

Favier Dubois, C. 2015. Continuidades y discontinuidades: el sesgo arqueológico del Holoceno medio en los valles pampeanos (Argentina) desde una mirada geoarqueológica. En Geoarqueología na America do Sul, editado por J. Rubin de Rubin, C.M. Favier Dubois y R.T. Da Silva, pp. 91-108. PUC, Goiás.

Favier Dubois, C., A. Massigoge y P. Messineo 2017. El Holoceno Medio en valles fluviales del sudeste pampeano: ¿Escasez de sitios o de unidades portadoras? Una perspectiva geoarqueológica. Revista del Museo de Antropología 10 (2):19-34.

Flegenheimer, N., C. Bayón, C. Scabuzzo, N. Mazzia, R. Vecchi, C. Weitzel, R. Frontini y M. Colombo 2010. EarlyHolocene human skeletal remains from the Argentinean pampas. Current Research in the Pleistocene 27:10-12.

Folguera, A., M. Etcheverría, M. A. Zárate, F. Miranda, A. J. Faroux y P. R. Getino 2015. Hoja Geológica 3963-I, Río Colorado. Provincias de La Pampa, Buenos Aires y Río Negro. Instituto de Geología y Recursos Minerales, Servicio Geológico Minero Argentino, Boletín 410. Buenos Aires.

García, A. 2005. Human occupation of the Central Andes of Argentina $\left(32^{\circ}-34^{\circ} \mathrm{S}\right)$ during the mid-Holocene. Quaternary International 132:61-70.

García, A., M. Zárate y M. Paez 1999. The Pleistocene/ Holocene transition and the human occupation in the Central
Andes of Argentina: Agua de la Cueva Locality. Quaternary International 53/54:43-52.

Garvey, R. 2008. A behavioral ecological approach to a proposed middle Holocene occupational gap. Before Farming $2(2): 1-14$.

Gil,A., M.Zárate y G. Neme 2005. Mid-holocene Paleoenvironments and the archaeological record of southern Mendoza, Argentina. Quaternary International 132:81-94.

Giraut, M., C. Lupano, C. Schulz y C. Rey 2006. Cartografía Hídrica Superficial Digital de la Provincia de La Pampa. Actas del III Congreso Argentino de la Ciencia Cartográfica y X Semana Nacional de Cartografía. CD-Rom. IGM, Buenos Aires.

Gómez, E. y G. Perillo 1995. Submarine outcrops underneath shoreface connected sand ridges, outer Bahía Blanca Estuary, Argentina. Quaternary of South America and Antarctica Peninsula 9 (3):23-37.

González, A. 1960. La estratigrafía de la gruta de Intihuasi (Prov. de San Luis, R.A.) y sus relaciones con otros sitios precerámicos de Sudamérica. Revista del Instituto de Antropología I:5-296.

González, M. 1984. Depósitos marinos del Pleistoceno superior en Bahía Blanca, Provincia de Buenos Aires, Argentina. Actas III del IX Congreso de Geología Argentina, pp.538-555. S.C. de Bariloche.

González, M., H. Panarello, H. Marino y S. Valencio 1983. Niveles marinos del Holoceno en el Estuario de Bahía Blanca (Argentina). Isótopos estables y microfósiles calcáreos como indicadores paleoambientales. Actas del Simposio "Oscilaciones del nivel del mar durante el Último Hemiciclo Deglacial en la Argentina", pp. 48-68. Mar del Plata.

González, M. y N. Weiler 1983. Ciclicidad de niveles marinos holocénicos en Bahía Blanca y en el Delta del Río Colorado (Provincia de Buenos Aires), en base a edades de Carbono-14. Actas del Simposio "Oscilaciones del nivel del mar durante el Último Hemiciclo Deglacial en la Argentina”, pp. 69-90. Mar del Plata.

Goñi, R.A. 1986-1987. Arqueología de sitios tardíos en el valle del río Malleo, Pcia. del Neuquén. Relaciones de la Sociedad Argentina de Antropología XVII (1):37-66.

Goodman, A. y J. Rose 1991. Dental enamel Hypoplasias as indicators of nutritional status. En Advances in Dental Anthropology, editado por M.A. Kelley y C.S. Larsen, pp. 279294. Wiley-Liss, Nueva York.

Gradin, C., C. Vayá, M. Quintana, H. Nami, A. Salvino, M. Berón y A. Aguerre 1984. Investigaciones Arqueológicas en Casa de Piedra. Pcia. de La Pampa. Dirección General de Cultura y Ente Ejecutivo Casa de Piedra, La Pampa.

Grill, S., A. Borromei, G. Martínez, M.A. Gutierrez, M.E. Cornou y D. Olivera 2007. Palynofacial analysis in alkaline soils and paleoenvironmental implications. The Paso Otero 5 archaeological site (Necochea district, Buenos Aires province, Argentina). Journal of South American Earth Sciences 24:3447.

Grimm, E.C., S. Lozano-García, H. Behling y V. Markgraf 2001. Holocene vegetation and climate variability in the Americas. En Interhemispheric Climate Linkages, editado por V. Markgraf, pp. 325-370. Academic Press, San Diego. 
Grosjean, M., C. Santoro, L. Thompson, L. Nuñez y V. Standen 2007. Mid-Holocene climate and culture change in the south central Andes. En Climate Change and Cultural Dynamics: A Global Perspective on Mid-Holocene Transitions, editado por D. Anderson, K. Maasch y D. Sandweiss, pp. 51-115. Academic Press, Londres.

Hillson, S. 1996. Dental Anthropology. Cambridge University Press, Cambridge.

Holliday, V., G. Martínez, E. Johnson y B. Buchanan 2003. Geoarchaeology of Paso Otero 5 (Pampas of Argentina). En Where the South Winds Blow. Ancient Evidence of Paleo South Americans, editado por L. Miotti, M. Salemme y N. Flegenheimer, pp. 37-43. Center for the Study of the First Americans, Center for the Study of the First Americans, College Station, Texas.

Instituto Nacional de Tecnología Agropecuaria (INTA) 1980. Inventario Integrado de los Recursos Naturales de la Provincia de La Pampa. Clima, Geomorfología, Suelo y Vegetación. Universidad Nacional de La Pampa, Buenos Aires.

Iriondo, M. 1990. A late Holocene dry period in the Argentina plains. Quaternary of South America and Antarctic Peninsula 7:198-218.

Iriondo, M. y N. García 1993. Climatic variations in the Argentine Plains during the last 18,000 years. Palaeogeography, Palaeoclimatology, Palaeoecology 101:209- 220.

Iriondo, M. y D. Kröling 1995. El sistema eólico pampeano. Comunicaciones del Museo Provincial de Ciencias Naturales "Florentino Ameghino" 5 (1):1-68.

Isla, F., J. Fasano, L. Ferrero, M. Espinosa y E. Ischinack 1986. Late Quaternary marine estuarine sequences of the southeastern coast of Buenos Aires Province, Argentina. Quaternary of South America and Antarctic Peninsula 4:137-157.

Jackson, D. 2002. Cazadores y Recolectores del Holoceno Medio del Norte Semiárido de Chile. Tesis para optar al grado de Magíster en arqueología. Departamento de Antropología, Facultad de Ciencias Sociales, Universidad de Chile, Santiago.

Johnson, E., G. Politis, G. Martínez, W. Hartwell, M. Gutiérrez y H. Haas 1998. The radiocarbon chronology of Paso Otero 1 in the Pampean Region of Argentina. Quaternary of South America Antarctic Peninsula 11:15-25.

Krömer, R. 1996. Los sedimentos cuaternarios del sudeste de la llanura mendocina. Implicancias paleoclimáticas. Multequina 5:49-55.

Laporte, L. 2014. Estudio del ajuar funerario de los entierros humanos. En Estado Actual de las Investigaciones en el Sitio Arqueológico Arroyo Seco 2, editado por G. Politis, M. Gutiérrez y C. Scabuzzo, pp. 393-415. Universidad Nacional del Centro de la Provincia de Buenos Aires, Facultad Ciencias Sociales, Tandil.

Loponte, D., A. Acosta y P. Tchilinguirian 2010. Avances en la arqueología de la Pampa Ondulada: sitios Hunter y Meguay. En Arqueología Argentina en el Bicentenario de la Revolución de Mayo, editado por J. R. Bárcena y H. Chiavaza, Tomo V, pp. 1811-1826. INCIHUSA, Mendoza.

Lucero, E., M. Berón, G. Gonzalez y A.N. Diana 2020. Osteobiografía de un individuo del Holoceno Medio, recuperado en la Localidad Arqueológica Cerro de los Viejos (Departamento Caleu Caleu, La Pampa). Revista del Museo de Antropología 13 (3):193-206.
Madrid, P. 1991. Infraestructura indígena para el mantenimiento y traslado de ganado introducido: el caso del Sistema Serrano de Pillahuinco, provincia de Buenos Aires. Boletín del Centro 3:65-71.

Madrid, P., G. Politis, R. March y M. Bonomo 2002. Arqueología microrregional en el Sudeste de la Región Pampeana argentina: el curso del río Quequén Salado. Relaciones de la Sociedad Argentina de Antropología XXVII:327-355.

Maier, M. y E. Tomasini 2018. Análisis No Invasivo In Situ de Objetos de la Colección Etnográfica y Arqueológica del Museo Etnográfico Juan B Ambrosetti. Instituto de Investigaciones en Arte y Cultura Doctor Norberto Griffa, Universidad Nacional de Tres de Febrero, Buenos Aires.

Mancini, M.V., M.M. Paez, A.R. Prieto, S. Stutz, M. Tonello y I. Vilanova 2005. Mid-Holocene climatic variability reconstruction from pollen records. Quaternary International 132:47-59.

Mandrini, R. 1984. Los Araucanos de las Pampas en el Siglo XIX. Centro Editor de América Latina, Buenos Aires.

Mann, M. E. 2002. The value of multiple proxies. Science 297:1481-1482.

Markgraf, V. 1983. Late and postglacial vegetational and paleoclimatic changes in subantartic temperate, and arid environments in Argentina. Palynology 7:43-70.

Markgraf, V. 1989. Palaeoclimates in central and south America since 18,000 BP based on pollen and lake-level records. Quaternary Science Reviews 8:1-24.

Markgraf, V. 1993. Climatic history of central and the South America since 18.000 yr. BP.: comparison of pollen records and models simulations. En Global Climates Since the Last Glacial Maximum, editado por H. Wright, J. Kutzbach, T. Webb, W. Ruddiman, F. Street-Perrot y P. Bartlei, pp. 357-385. University of Minneapolis Press, Minneapolis.

Martínez, G. 1999. Tecnología, Subsistencia y Asentamiento en el Curso Medio del Río Quequén Grande: Un Enfoque Arqueológico. Tesis para optar al grado de Doctor. Facultad de Ciencias Naturales y Museo, Universidad Nacional de La Plata, La Plata.

Martínez, G. 2002. Organización y cambio en las estrategias tecnológicas: Un caso arqueológico e implicaciones comportamentales para la evolución de las sociedades cazadorasrecolectoras pampeanas. En Perspectivas Integradoras entre Arqueología y Evolución. Teoría, Método y Casos de Aplicación, Serie Teórica 1, editado por G. Martínez y J.L. Lanata, pp. 121156. INCUAPA, Universidad Nacional del Centro de la Provincia de Buenos Aires, Olavarría.

Martínez, G. 2017. Discusión. En Arqueología de CazadoresRecolectores del Curso Inferior del Río Colorado (Provincia de Buenos Aires, Argentina). Aportes al Conocimiento de las Ocupaciones Humanas Pampeano-Patagónicas, editado por G. Martínez, pp. 255-297. INCUAPA-CONICET-UNICEN, Olavarría.

Martínez, G. y G.A. Martínez 2011. Late Holocene environmental dynamics in fluvial and aeolian depositional settings: Archaeological record variability at the lower Basin of the Colorado River, Argentina. Quaternary International 245:89-102.

Martínez, G. y G. Flensborg 2018. Nuevos contextos funerarios en la transición pampeano-patagónica oriental (Pcia. de Buenos Aires, Argentina): aportes al Holoceno Medio y Tardío inicial. Chungara Revista de Antropología Chilena 50 (3):441-458. 
Martínez, G., G. Flensborg y P. Bayala 2012. Primeras evidencias de restos óseos humanos en el curso inferior del río Colorado durante el Holoceno medio: sitio Cantera de Rodados Villalonga (pdo. de Patagones, pcia. de Buenos Aires). Cazadores Recolectores del Cono Sur. Revista de Arqueología 6:101-113.

Martínez, G., L. Prates, G. Flensborg, L. Stoessel, A. Alcaráz y P. Bayala 2015. Radiocarbon trends in the Pampean region (Argentina). Biases and demographic patterns during the final Late Pleistocene and Holocene. Quaternary International 356:89-110.

Martínez, G.A., D.S. Marchionni, M.O. Farenga y S.A. Gavilán 2012. Aportes de la geomática en el análisis geomorfológico de los "Bajos sin Salida" del área de transición pampeanopatagónica. Actas del Congreso Argentino de Teledetección (CAT 2012). Instituto de Recursos Minerales, Córdoba. https:// digital.cic.gba.gob.ar/handle/11746/2270.

Martínez, G.A., D. Mazzanti, C. Quintana, A. Zucol, M. Colobig, G. Hassan, M. Brea y E. Passeggi 2013. Geoarchaeological and paleoenvironmental context of the human settlement in the Eastern Tandilia Range, Argentina. Quaternary International 299:23-37.

Massigoge, A., J.M. Rodríguez, C.M. Favier Dubois, P.G. Steffan, M.N. Rodríguez y R.F. Torino 2014. Sitio Las Toscas 5: Un nuevo contexto arqueológico del Holoceno medio en el Área Interserrana de la Región Pampeana. Resúmenes del VII Congreso de Arqueología de la Región Pampeana Argentina, pp. 581. Rosario, Santa Fe.

Mazzanti, D., G.A. Martínez y C.A. Quintana 2015. Asentamientos del Holoceno medio en Tandilia oriental. Aportes para el conocimiento de la dinámica poblacional de la Región Pampeana, Argentina. Relaciones de la Sociedad Argentina de Antropología XL (1):209-231.

Mazzanti, D., G.A. Martínez, M. Colobig, F. Zucol, E. Passeggi, M. Brea, G. Bonnat, G. Hassan, J. Soria, J. Vera y C. Quintana 2013. Avances en los estudios arqueológicos, geoarqueológicos y paleoambientales en las sierras de Tandilia. Resultados preliminares en Alero El Mirador y Abrigo La Grieta. Revista del Museo de La Plata, Sección Antropología 13 (87):59-76.

Medus, N. y F. Aráoz 1982. Espacios áridos en la provincia de La Pampa. Intentos de puesta en valor. Revista Geográfica 95:146-163.

Medus, N., R. Hernández y W. Cazenave 1982. Geografía de La Pampa. Editorial Extra, Santa Rosa.

Mehl, A., A. Tripaldi y M.A. Zárate 2018. Late Quaternary Aeolian and fluvial-aeolian interaction deposits from southwestern Pampas of Argentina, southern South America. Palaeogeography, Palaeoclimatology, Palaeoecology 511:280-297.

Melchor, R.N. y E.J. Llambías 2004. Hoja Geológica 3766-I, Santa Isabel. Provincia de La Pampa. Instituto de Geología y Recursos Minerales, Servicio Geológico Minero Argentino, Boletín 344. Buenos Aires.

Melo, W.D., R. Schillizzi, G.M.E. Perillo y M.C. Piccolo 2003. Influencia del área continental pampeana en la evolución morfológica del estuario de Bahía Blanca. Latin American Journal of Sedimentology and Basin Analysis 10 (1):39-52.

Méndez, C., A. Gil, G. Neme, A. Nuevo Delaunay, V. Cortegoso, C. Huidobro, V. Durán, y A. Maldonado 2015. Mid Holocene radiocarbon ages in the Subtropical Andes $\left(\sim 29^{\circ}\right.$ - $35^{\circ} \mathrm{S}$ ), climatic change and implications for human space organization. Quaternary International 356:15-26.
Méndez, C., S. Grasser, D. Jackson, A. Troncoso y B. Santander 2016. Ocupaciones humanas del Holoceno Medio en los Andes del norte semiárido de Chile ( $31^{\circ} \mathrm{S}$, Combarbalá): Función del sitio e implicancias para el uso regional del espacio. Chungara Revista de Antropología Chilena 48 (2):225-241.

Messineo, P., M. Tonello, S. Stutz, A. Tripaldi, N. Scheifler, N. Pal, G. Sánchez Vuichard y D. Navarro 2019. Human occupation strategies and related environmental-climate during the middle and late Holocene in central Pampas of Argentina. The Holocene 29 (2):244-261.

Miotti, L. 2006. La fachada atlántica, como puerta de ingreso alternativa de la colonización humana de América del Sur durante la transición Pleistoceno/Holoceno. Actas del $2^{\circ}$ Simposio Internacional del Hombre Temprano en América, editado por J.C. Jiménez López, pp. 155-188. Instituto Nacional de Antropología e Historia, Consejo Nacional para la Cultura y las Artes, México DF.

Miotti, L., E. Terranova, D. Hermo y R. Blanco 2015. Edenes en el Desierto. Señales de caminos y lugares en la historia de la colonización de patagonia argentina. Antípoda. Revista de Antropología y Arqueología 23:161-185.

Muhs, D. y M.A. Zárate 2001. Late Quaternary eolian records of the Americas and their paleoclimatic significance. En Interhemispheric Climate Linkages, editado por V. Markgraf, pp. 183-216. Academic Press, San Diego.

Neme, G. y A. Gil 2008. Biogeografía humana en los Andes meridionales: Tendencias arqueológicas en el sur de Mendoza. Chungara Revista de Antropología Chilena 40:5-18.

Neme, G. y A. Gil 2009. Human occupation and increasing mid-Holocene aridity. Current Anthropology 50 (1):149-163.

Neme, G., A. Gil, R. Garvey, C. Llano, A. Zangrando, F. Franchetti, C. De Francesco y T. Michieli 2011. El registro arqueológico de la gruta de El Manzano y sus implicancias para la arqueología de nordpatagonia. Magallania 39 (2):243-265.

Núñez, L. y C. Santoro 1988. Cazadores de la puna seca y salada del área centro-sur andina (Norte de Chile). Estudios Atacameños 9:11-60.

Núñez, L., M. Grosjean e I. Cartagena 1999. Un ecorefugio oportunístico en la puna de Atacama durante eventos áridos del Holoceno Medio. Estudios Atacameños 17:125-174.

Núñez, L., M. Grosjean e I. Cartagena 2002. Human dimensions of Late Pleistocene/Holocene arid events in Southern South America. En Interhemisferic Climate Linkages, editado por V. Markgraf, pp. 105-117. Academic Press, New York.

Paez, F., M. Berón, E. Lucero y M. Carrera Aizpitarte 2020. Análisis formal del mortero múltiple ubicado en Cerro de los Viejos (Departamento Caleu Caleu, La Pampa, Argentina). Revista del Museo de Antropología 13 (1):95-104.

Paez, F., R. Curtoni y M. Berón 2019. Cerro de Los ViejosRepresas. Relatoría de las observaciones, Campaña abril 2019. Informe a la Dirección de Patrimonio de la Secretaría de Cultura, Provincia de La Pampa.

Pascual, R. y P. Bondesio 1981. Sedimentitas cenozoicas. En Geología y Recursos Naturales de la Provincia de San Luis, editado por M. Yrigoyen, pp.117-154. Relatorio del VIII Congreso Geológico Argentino, Buenos Aires.

Pedrotta, V. 2016. Estrategias indígenas de captura y manejo del ganado cimarrón en las Sierras Septentrionales bonaerenses: 
las construcciones de piedra Cerro Guacho I y Cerro Guacho II. Arqueología 22 (2):269-289.

Piana, E. 1981. Toponimia y Arqueología del Siglo XIX. Eudeba, Buenos Aires.

Pinto Rodríguez, J. 1996. Integración y desintegración de un espacio fronterizo. La Araucanía y las Pampas, 1550-1900. En Araucanía y Pampas. Un Mundo Fronterizo en América del Sur, editado por J. Pinto Rodríguez, pp. 11-46. Universidad de la Frontera, Temuco.

Politis, G. 1986. Investigaciones arqueológicas en el área Interserrana Bonaerense. Etnia 32:7-52.

Politis, G. 2008. The Pampas and Campos of South America. En Handbook of South American Archaeology, editado por H. Silverman y W.H. Isbell, pp. 235-260, Springer, Nueva York.

Politis, G. 2014. Discusión y consideraciones finales. En Estado Actual de las Investigaciones en el Sitio Arqueológico Arroyo Seco 2 (Partido de Tres Arroyos, Provincia de Buenos Aires, Argentina), editado por G. Politis, M. Gutiérrez y C. Scabuzzo, pp. 439-459. Universidad Nacional del Centro de la Provincia de Buenos Aires, Facultad Ciencias Sociales, Tandil.

Politis, G., G. Barrientos y T.W. Stafford 2011. Revisiting Ameghino: New 14C dates from ancient human skeletons from the Argentine pampas. En Peuplements et Prehistoire en Ameriques, editado por D. Vialou, pp. 43-53. Éditions du Comité des travaux historiques et scientifiques, París.

Politis, G. y M. Bonomo 2011. Nuevos datos sobre el "hombre fósil" de Ameghino. En Vida y Obra de Ameghino, editado por J. Fernicola, A. Prieto y D. Lazo, pp. 101-119. Asociación Paleontológica Argentina, Publicación Especial 12, Buenos Aires.

Politis, G., M. Gutiérrez y C. Scabuzzo (eds.) 2014. Estado Actual de las Investigaciones en el Sitio Arroyo Seco 2 (Pdo. de Tres Arroyos, Pcia. de Buenos Aires, Argentina). Universidad Nacional del Centro de la Provincia de Buenos Aires, Facultad Ciencias Sociales, Tandil.

Politis, G., C. Scabuzzo y R. Tykot 2009. An approach to prehispanic diets in the pampas during early/middle Holocene. International Journal of Osteoarchaeology 19:266-280.

Prates, L. y M. Bonomo 2017. Los ambientes acuáticos en arqueología. Arqueología 23 (3):11-33.

Prieto, A.R. 1996. Late Quaternary vegetational and climatic changes in the Pampa grassland of Argentina. Quaternary Research 45:73-88.

Quattrocchio, M., A.M. Borromei, C.M. Deschamps, S.C. Grill y C.A. Zavala 2008. Landscape evolution and climate changes in the Late Pleistocene-Holocene, southern Pampa (Argentina): Evidence from palynology, mammals and sedimentology. Quaternary International 181:123-138.

Salemme, M. y M. Berón 2003. Análisis intrasitio del componente faunístico del sitio 1 de la Localidad Tapera Moreira. Diferencias y tendencias. Actas del XIII Congreso Nacional de Arqueología Argentina Vol. III, editado por F. Oliva, pp. 325-345. Editorial Brujas, Córdoba.

Sato, A., A. Ortiz Suárez, E. Llambías, C. Cavarozzi, V. Sánchez, R. Varela y C. Prozzi 1996. Los plutones Pre-Oclóyicos del Sur de la Sierra de San Luis: Arco Magmático al inicio del Ciclo Famatiniano. Actas 5 del $13^{\circ}$ Congreso Geológico Argentino y $3^{\circ}$ Congreso de Exploración de Hidrocarburos, pp. 259-272. Buenos Aires.
Scabuzzo, C. y G. Politis 2010. Entierros secundarios del Holoceno temprano y medio de la región pampeana. Nuevos datos del sitio Arroyo Seco 2. Cazadores-Recolectores del Cono Sur. Revista de Arqueología 4:135-155.

Scabuzzo, C. y G. Politis 2019. El registro bioarqueológico del sitio Arroyo Seco 2. Nuevos datos e interpretaciones. Libro de Resúmenes del XX Congreso Nacional de Arqueología Argentina, pp. 215-216. Universidad Nacional de Córdoba, Córdoba.

Schäbitz, F. 2003. Estudios polínicos del Cuaternario en las regiones áridas del sur de Argentina. Revista del Museo Argentino de Ciencias Naturales 5:291-299.

Scheuer, L. y S. Black 2000. Developmental Juvenile Osteology. Academic Press, Londres.

Schlanger, S. 1992. Recognizing persistent places in Anasazi settlement systems. En Space, Time and Archaeological Landscape, editado por J. Rossignol y L. Wandsnider, pp. 91112. Plenum Press, New York.

Schobinger, J. 1959. Esquema de la Prehistoria Argentina. Ampurias 21:29-67.

Smith, H. 1991. Standards of human tooth formation and dental age assessment. En Advances in Dental Anthropology, editado por M. Kelley y C. Larsen, pp. 143-168. Wiley-Liss, Nueva York.

Stoessel, L. 2015. Tendencias preliminares sobre el consumo de peces durante el Holoceno medio en el área de transición Pampeano-Patagónica oriental (provincia de Buenos Aires). Archaeofauna 24:103-117.

Tickyj, H. y E.J. Llambías 1994. EI gneis milonitico del Cerro de Los Viejos ( $38^{\circ} 28^{\prime}$ S $\left.-64^{\circ} 26^{\prime} 0\right)$, provincia de La Pampa, Argentina. Evidencia de un corrimiento en el Carbonífero inferior. Actas $7^{\circ}$ Congreso Geológico Chileno, Tomo 2, pp. 1239-1243. Universidad de Concepción, Departamento de Ciencias de la Tierra, Concepción.

Tickyj, H., L.V. Dimieri, E.J. Llambías y A.M. Sato 1997. Cerro de Los Viejos ( $38^{\circ} 28^{\prime} \mathrm{S}-6^{\circ} 26^{\prime}$ 0): cizallamiento dúctil en el sudeste de La Pampa. Revista de la Asociación Geológica Argentina 52 (3):311-321.

Tonello, M.S. y A.R. Prieto 2010. Tendencias climáticas para los pastizales pampeanos durante el Pleistoceno tardíoHoloceno: Estimaciones cuantitativas basadas en secuencias polínicas fósiles. Ameghiniana 47 (4):501-514.

Tonni, E.P., A.L. Cione y A.J. Figini 1999. Predominance of arid climates indicated by mammals in the pampas of Argentina during the Late Pleistocene and Holocene. Palaeogeography, Palaeoclimatology, Palaeoecology 147:257-281.

Tonni, E.P., R.A. Huarte, J.E. Carbonari y A.J. Figini 2003. New radiocarbon chronology for the Guerrero Member of the Luján Formation (Buenos Aires, Argentina): palaeoclimatic significance. Quaternary International 109-110:45-48.

Torres, S., G. Darrigran y C. Damborenea 2012. Distribution of the genus Diplodon (Mollusca: Bivalvia: Hyriidae) in Argentina by the use of Biological Collections. Actas del $7^{\circ}$ Congreso de Medio Ambiente, pp. 1-13. Universidad Nacional de La Plata, La Plata.

Torres, S., L. Cao, D.E. Gutiérrez Gregoric, M. de Lucía, F. Brea y G. Darrigran 2018. Distribution of the Unionida (Bivalvia, Paleoheterodonta) from Argentina and its conservation in the Southern Neotropical Region. PLOS ONE 13(9), e0203616. 
Ubelaker, D. 1982. Human Skeletal Remains. Excavation, Analysis, Interpretation. Taraxacum, Washington.

Veth, P. 1993. Islands in the Interior. The Dynamics of Prehistoric Adaptations within the Arid Zone of Australian. International Monographs in Prehistory, Ann Arbor.

Veth, P. 2005. Cycles of aridity and human mobility. Risk minimization among late Pleistocene foragers of the Western Desert, Australia. En Desert Peoples: Archaeological perspectives, editado por P. Veth, M. Smith y P. Hiscock, pp. 100-115. Blackwell Publishing, Malden.

Villagrán, C. y L. Hinojosa 1997. Historia de los bosques del sur de Sudamérica II: análisis biogeográfico. Revista Chilena de Historia Natural 70:241-267.

Walker, M., M. Berkelhammer, S. Björck, L. Cwynar, D. Fisher, A. Long, J. Lowe, R. Newnham, S. Rasmussen y H. Weiss 2012 Formal subdivision of the Holocene Series/Epoch: a Discussion Paper by a Working Group of INTIMATE (Integration of icecore, marine and terrestrial records) and the Subcommission on Quaternary Stratigraphy (International Commission on Stratigraphy). Journal of Quaternary Science 27:649-659.

White, C., F. Longstaffe y K. Law 2004. Exploring the effects in ancient Nubian bones and teeth. Journal of Archaeological Science 31:233-250.

Yacobaccio, H. y M. Morales 2005. Mid-Holocene environment and human occupation of the Puna (Susques, Argentina). Quaternary International 132:5-14.

Zárate, M. 1997. Late Pleistocene geoarchaeology of the southern pampas, Buenos Aires, Argentina. Anthropologie 35:197-205. of environment, physiology and diet on oxygen isotope ratios

Zárate, M. 2002. Los ambientes del tardiglacial y Holoceno en Mendoza. En Entre Montañas y Desiertos: Arqueología del Sur de Mendoza, editado por A. Gil. y G. Neme, pp. 19-42. Sociedad Argentina de Antropología, Buenos Aires.

Zárate, M. 2010. El paisaje pampeano a través del tiempo. En Mamül Mapu: Pasado y Presente desde la Arqueología Pampeana, editado por M. Berón, L. Luna, M. Bonomo, C. Montalvo, C. Aranda y M. Carrera Aizpitarte, pp. 19-32. Editorial Libros del Espinillo, Ayacucho.

Zárate, M. y N. Flegenheimer 1991. Geoarchaeology of the Cerro La China Locality (Buenos Aires, Argentina). Site 2 and site 3. Geoarchaeology. An International Journal 6 (3):273-294.

Zárate, M., G. Neme y A. Gil 2005. Mid Holocene paleoenvironments and human occupation in southern South America. Quaternary International 132:1-3.

Zárate, M., M. Espinosa y L. Ferrero 1998. Paleoenvironmental implications of a Holocene diatomite. Quaternary of South America and Antarctic Peninsula 12:135-52.

Zárate, M. y M. Paez 2002. Los paleoambientes del PleistocenoHoloceno en la Cuenca del Arroyo La Estacada, Mendoza. En IANIGLA, 30 Años de Investigación Básica y Aplicada en Ciencias Ambientales, editado por D. Trombotto y R. Villalba, pp.117-121. IANIGLA, Mendoza.

Zárate, M. y A. Tripaldi 2012. The aeolian system of central Argentina. Aeolian Research 3 (4):401-417.

\section{Notas}

${ }^{1}$ El protocolo de muestreo adoptado por el equipo de trabajo fue definido luego de realizar testeos en huesos humanos en el Instituto de Química Física de los Materiales, Medio Ambiente y Energía (INQUIMAE) de la Universidad de Buenos Aires, comprobándose el escaso o nulo contenido de colágeno. Por ese motivo se adoptó la decisión de realizar los análisis radiocarbónicos e isotópicos a partir de dientes, dado que el proceso de desarrollo de la dentición es relativamente constante entre poblaciones y se ve poco influenciado por condicionamientos ambientales. Se decidió, siempre que fuera posible, seleccionar terceros molares dado que la calcificación de su corona se da entre los 10 y 15 años de edad (Scheuer y Black 2000; Smith 1991; Ubelaker 1982), lo que permite evitar la incidencia en los resultados isotópicos de los valores de la dieta y de la ingesta de agua de la madre, incorporados a través de la lactancia (White et al., 2004). De ser posible se selecciona el tercer molar superior izquierdo, a fin de neutralizar probables repeticiones de mediciones en un mismo individuo, dado el alto grado de fragmentación y mezcla de elementos óseos y dentales en un repositorio de alta complejidad como el cementerio Chenque I (Lihué Calel, La Pampa; Berón et al. 2009, 2013).

${ }^{2}$ Los valores isotópicos fueron reportados en partes por mil $(\%)$ según distintos estándares internacionales: $\delta^{13} \mathrm{C}$ según el standard Pee Dee Belemnite (V-PDB), $\delta^{15} \mathrm{~N}$ según el standard AIR, y $\delta^{18} \mathrm{O}$ según Viena Standard Mean Ocean Water (VSMOW) (Ambrose 1993).

${ }^{3}$ Las mediciones fueron realizadas con un equipo portátil de espectroscopia de fluorescencia de rayos X (pFRX) marca Bruker modelo Tracer III SD con las siguientes condiciones de análisis: corriente de $11 \mathrm{~mA}$, potencia de $40 \mathrm{kV}$ y uso de un filtro de teflón (Maier y Tomasini 2018).

${ }^{4}$ Teledyne Isotopes, Westwood, New Jersey, USA. 
